\title{
Functional assessment of long-term deficits in rodent models of traumatic brain injury
}

Traumatic brain injury (TBI) ranks as the leading cause of mortality and disability in the young population worldwide. The annual US incidence of TBI in the general population is estimated at 1.7 million per year, with an estimated financial burden in excess of US $\$ 75$ billion a year in the USA alone. Despite the prevalence and cost of TBI to individuals and society, no treatments have passed clinical trial to clinical implementation. The rapid expansion of stem cell research and technology offers an alternative to traditional pharmacological approaches targeting acute neuroprotection. However, preclinical testing of these approaches depends on the selection and characterization of appropriate animal models. In this article we consider the underlying pathophysiology for the focal and diffuse TBI subtypes, discuss the existing preclinical TBI models and functional outcome tasks used for assessment of injury and recovery, identify criteria particular to preclinical animal models of TBI in which stem cell therapies can be tested for safety and efficacy, and review these criteria in the context of the existing TBI literature. We suggest that 2 months post-TBI is the minimum period needed to evaluate human cell transplant efficacy and safety. Comprehensive review of the published TBI literature revealed that only $32 \%$ of rodent TBI papers evaluated functional outcome $\geq 1$ month post-TBI, and only $10 \%$ evaluated functional outcomes $\geq 2$ months post-TBI. Not all published papers that evaluated functional deficits at a minimum of 2 months post-TBI reported deficits; hence, only $8.6 \%$ of overall TBI papers captured in this review demonstrated functional deficits at 2 months or more postinjury. A 2-month survival and assessment period would allow sufficient time for differentiation and integration of human neural stem cells with the host. Critically, while trophic effects might be observed at earlier time points, it will also be important to demonstrate the sustainability of such an effect, supporting the importance of an extended period of in vivo observation. Furthermore, regulatory bodies will likely require at least 6 months survival post-transplantation for assessment of toxicology/safety, particularly in the context of assessing cell abnormalities.

KEYWORDS: cell transplantation cognition functional assessment learning and memory Morris water maze neural stem cells review rodent behavioral tasks rodent models of neurotrauma traumatic brain injury

\section{Definition of traumatic brain injury}

Broadly defined, traumatic brain injuries (TBIs) encompass any injury resulting in altered brain function or brain pathology as the result of an external force. Under this definition, altered brain function includes any period of any one of the following: a decrease in or loss of consciousness; pre- or post-event memory loss (amnesia); neurological deficits such as confusion, slowed thinking or aphasia; or vision or sensory changes, loss of balance, muscle weakness or paralysis [1,2]. An individual need not lose consciousness to sustain a brain injury. A mild TBI, or concussion, can still damage the brain at the cellular level and increase the risk of neurodegenerative disorders such as Alzheimer's disease in the future [3]. Even persons experiencing a minor concussion that does not result in hospitalization can have persistent symptoms of headaches, anxiety and/or fatigue coupled with cognitive deficits in memory, concentration and/ or attention; this constellation of symptoms is referred to as postconcussion syndrome [4]. Not all individuals who sustain trauma to the head will experience a TBI, but anyone with a history of head trauma resulting in altered brain function can be said to have sustained a TBI [2].

Repetitive head injuries, even minor ones, can also lead to serious repercussions to the recipient - including permanent brain damage or death. Repetitive brain injury was initially termed 'punch drunk' syndrome [5], then 'traumatic encephalopathy' [6] or 'dementia pugilistica' [7] and finally 'chronic progressive traumatic encephalopathy of boxers' [8]. This terminology reflects the early characterization of repetitive brain injury in professional boxers. More recently, the resulting neuropsychological problems and underlying brain pathology seen in some professional athletes following repeated

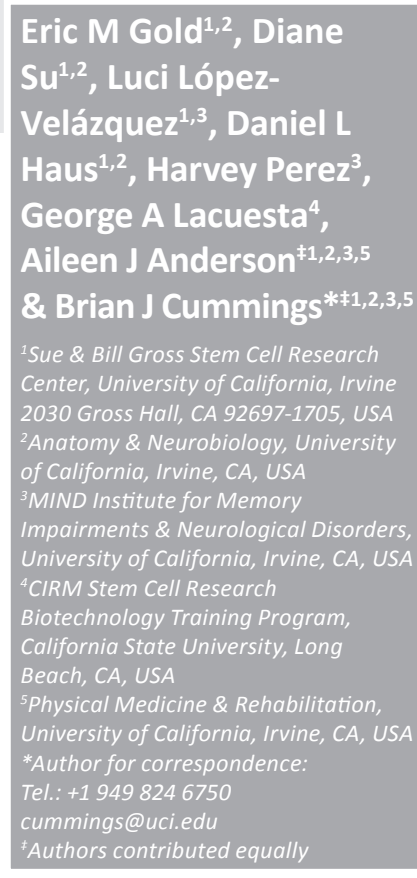

Regenerative Medicine 
brain trauma has been termed chronic traumatic encephalopathy (CTE). The first National Football League player diagnosed with CTE was 50 years old and had sustained multiple concussive injuries over a 17-year professional career [9]. Since then, numerous reports of CTE in athletes have been linked to a variety of professional contact sports [10].

\section{Incidence, prevalence \& cost estimates of TBI}

TBI is often referred to as a 'silent epidemic'; a status borne out by the fact that it ranks as the leading cause of mortality and disability in the young population worldwide [11]. Every $18.5 \mathrm{sec}-$ onds, someone in the USA suffers a TBI [12]. The annual incidence of TBI (new cases each year) in the general population was estimated at 1.7 million Americans per year (based on 2002-2006 data) [13]. This is higher than the incidence of Alzheimer's disease, Parkinson's disease and multiple sclerosis combined, and greater than the incidence of individuals diagnosed with brain, breast, colon, lung or prostate cancer combined [12]. Critically, these figures do not include military personnel. TBI-related injuries are the signature injury of military personnel who served in either the Iraq and/or Afghanistan wars. It is estimated that nearly $60 \%$ of all casualties among soldiers admitted to Walter Reed National Military Medical Center suffer from TBI [301]. The Department of Defense Medical Surveillance System estimated that the number of personnel who experienced some level of TBI between 2000-2012 was 266,810 [302].

During the same time period as US annual TBI incidence data (2002-2006), 1.1-1.4 million civilians per year were treated in US hospital emergency rooms for TBI, resulting in an average of 52,000 deaths per year [14]. Mortality in severe TBI cases remains approximately $30 \%$ [15]. Greater than $40 \%$ of US citizens with TBI have residual disability 1-year postinjury [16]. It is difficult to estimate the prevalence of TBI worldwide owing to sparse data, differing definitions and changing patterns over time [17]. The changing pattern is due to a variety of factors, including demographic/population shifts, the institution of modern safety measures and changes in reporting criteria, among others, which makes determining the worldwide incidence and prevalence of TBI difficult. Prevalence estimates for long-term TBI-related disability in the US range from 3.2 million [16] to 5.3 million [18] individuals; thus, nearly one out of every 50-75 American civilians are currently living with disabilities from TBI. Direct medical costs coupled with rehabilitation and lost productivity result in a financial burden estimated to be in excess of US $\$ 75$ billion a year in the US (in 2010 dollars) $[19,20]$. This number would be much higher when projections are made for lost productivity of the care-givers. In a study of postTBI employment rates among adults with TBI who received inpatient care and rehabilitation at the Traumatic Brain Injury Model Systems (TBIMS) center program at the University of Missouri, only $36 \%$ of those who were employed at the time of their injury were employed 2 years postinjury. The percentage of some form of public assistance rose from $18 \%$ preinjury to $38 \%$ at 2 years postinjury (data were not broken down by injury severity) [21].

\section{Underlying pathophysiology of TBI}

Primary TBI reflects the early damage that is the direct result of the physical displacement of brain structures, including contusion, vascular injury and axon shearing. Secondary TBI reflects damage that is an indirect result of the initial trauma; secondary damage therefore encompasses a variety of cellular processes that contribute to the progressive loss of cells and damage to underlying pathways over hours, days and weeks [22]. TBI can also be classified as focal or diffuse in type, with the latter accounting for up to $70 \%$ of TBI in humans [23]. The forces producing focal and diffuse TBI are notably different. Clinically, focal TBI results from a direct impact to the skull (e.g., following a fall that causes compression of the brain region underlying the impact [coup] and rebound impact to the brain region directly opposite [contrecoup]) [24,25]. As a result, the location of the impact is directly related to the neuroanatomical locations of damage and resulting neurological deficits. Pathophysiologically, the principal characteristics of focal TBI are laceration, contusion and hematoma.

By contrast, diffuse TBI results from rapid acceleration-deceleration of the head, for example following a high-speed motor vehicle accident, which causes widely distributed white matter, vascular and hypoxic-ischemic damage [24,25]. Macroscopically, the diffuse TBI brain presents few abnormalities; the true extent of axonal damage is only detected using markers or modalities sensitive to abnormalities in axons and white matter structures [26-28]. In situ, this includes staining for neurofilament or APP. In vivo, this includes analysis by diffusion tensor MRI. Clinical studies suggest that diffuse TBI 
results in progressive, chronic atrophy of white matter that may continue for years postinjury [29]. This is thought to be associated with detachment of distal axons from the cell body, resulting in the formation of retraction bulbs, a histological hallmark of diffuse injury. In experimental animal models, the underlying processes are termed traumatic axonal injury, and include changes in axolemma permeability, activation of proteases, cytoskeletal degradation and impairment of axonal transport [27]. Axonal damage in diffuse TBI is thought to result from shearing and compressive forces that exceed the maximum elasticity potential of axons. As a result, the direction of shear and strain forces in diffuse TBI plays a critical role in the severity of damage. Critically, however, MRI studies suggest that $50 \%$ or more of patients with moderate-to-severe TBI exhibit a mixed etiology, in which both focal lesions and diffuse axonal injury are observed [30]. These complex and mixed clinical observations suggest that, despite the contribution of distinct pathophysiological mechanisms to focal neuronal loss versus diffuse axonal pathology, the distinction between focal and diffuse TBI is an artificial one [24]. This blurred distinction highlights the importance of animal model selection, the need to replicate positive findings in more than one model and the potential need for combinatorial therapeutic approaches.

\section{Predictive validity of preclinical animal models for clinical translation}

It is clear that TBI in humans causes a wide range of damage and deficits. Basic and preclinical animal research attempts to model aspects of TBI pathology using different injury paradigms and measuring different types of motor and cognitive outcomes. Common to most injury paradigms are two of the main pathological hallmarks of TBI: neuronal cell death and white matter damage. Basic and preclinical TBI research has focused heavily on strategies to attenuate the early expansion of damage. However, although even a modest improvement in outcome for patients would have significant quality of life benefits and financial benefits, no therapy has yet to be found to improve outcomes in TBI patients. To date, there have been 45 Phase II or III clinical trials in the USA for a drug or procedure (e.g., hypothermia or hyperbaric oxygen) to treat TBI; yet, there are still no US FDA-approved therapies for TBI [303]. This failure rate has highlighted the necessity of re-evaluating both clinical translation strategies and preclinical models.
In part, these failures have been suggested to result from heterogeneity in the clinical face of TBI. As a result, the reliance of clinical trials incorporating broad inclusion criteria and the use of preclinical data from highly homogeneous animal models may be a significant contributing factor in trial failure [31]. Experience from the stroke field suggests a relevant and cautionary tale, where a high rate of failure in translation from bench to bedside led to the formulation of criteria for the conduct and evaluation of preclinical research supporting clinical trial initiation (the Stroke Treatment Academic Industry Roundtable [STAIR] criteria) [32,33], as well as standards to ensure that the design of clinical trials reflects, as accurately as possible, the preclinical data and models available [32,33]. More recently, parallel criteria have been established by NIH. In August 2011, the National Institute of Neurological Disorders and Stroke [NINDS] released formal guidelines for the conduct of preclinical and clinical research, called the RIGOR criteria [NOT-NS-11-023] [304]. Both sets of criteria are designed to improve preclinical study design and enhance transparency of study reporting. For example, the RIGOR guidelines re-emphasize the basics of good experimental design, including: rational selection of models, route/timing of interventions and study end points; adequacy of controls, sample size and statistical methods; appropriate blinding, randomization and complete data reporting; data reproducibility/replication and verification of biological activity; consideration of alternative interpretations/hypotheses; discussion of effect sizes; and disclosure of conflicts of interest.

While, if consistently applied, STAIR and RIGOR criteria may improve the success of clinical translation over time, it may also be the case that a mismatch between preclinical models and the human condition can contribute to translation failure. This latter issue may be particularly critical for the advent of stem cell translational approaches for neurological disease and injury, which is our focus in the following sections.

\section{Criteria for predictive models of TBI $\&$ assessment of stem cell therapies}

The rapid progression of stem cell research in the last 15 years has opened a new aspect of regenerative medicine research and clinical translation for neurological disease $\&$ injury. Stem cell or other cellular therapy trials have either been completed or are still underway for the treatment of patients with Batten disease, spinal cord injury, Pelizaeus-Merzbacher disease (a fatal 
neurodegenerative disorder of myelin), amyotrophic lateral sclerosis, Huntington's disease, Parkinson's disease and ischemic stroke [34]. Stem cell approaches to regenerative medicine for CNS disorders are thought to proffer several broad mechanisms of action: immune-modulation of the host environment; trophic factor secretion in the local microenvironment; and/or underlying functional integration with the injured host following terminal differentiation of neural stem cells (NSCs) into neurons, astrocytes and/or oligodendrocytes. Critically, these mechanisms need not be mutually exclusive. In our experience, human NSCs (hNSCs) have the potential to simultaneously target neuronal replacement and white matter repair, to replenish lost cells following injury and/or to restore myelination of demyelinated axons [35,36].

While stem cell therapy strategies for TBI may offer the possibility of a new and mechanistically combinatorial approach, testing donor cell populations in animal models will add to the complexity of the criteria necessary for preclinical animal models with good predictive validity for clinical translation. In particular, at least two conditions would need to be met for any relevant preclinical model to enable evaluation of the success or failure of a therapeutic stem cell approach. First, a model in which sufficient engraftment of donor human cells can be achieved to reliably test safety and efficacy across a xenotransplantation barrier will be necessary; this requirement will likely require immunodeficient animal models, or dramatically improved methods of achieving adequate immunosuppression [37]. Second, a model in which sufficient time duration from transplant to assessment allows for the potential functional impact is necessary, so that either improvement (efficacy) or determent (safety) can be measured. In the case of TBI, the persistence of sustained deficits that can be reliably measured are an especially critical variable in this context. Human donor cells, in particular, may require a significant period of time for proliferation, migration, differentiation and integration; the time required for these processes can be anticipated to be an essential variable in determining the effect (or not) of donor cells on functional integration.

Critically, based on our experience with hNSCs and spinal cord injury [35,36,38,39], we would predict that sustained deficits post-TBI of at least 1 month, and more likely at least 2 months postinjury, are needed to allow for detection of cell transplant mediated functional effects if such effects are via integration and not via trophic-mediated mechanisms. Even in the case of either immune modulation or trophic factors, functional improvements at greater than 1 month postinjury would be desirable. As many TBI studies have focused on short-term outcomes, it is unclear which of the existing TBI models may meet these criteria to support safety and efficacy studies, particularly in the context of long-term deficits.

Accordingly, the goal of this review was to ascertain if there is an optimal combination of injury model and functional assessments that yields prolonged functional deficits, for example, $\geq 1$ month post-TBI, to enable detection of safety and efficacy in the context of stem cell transplantation strategies. Toward this end, we summarize current animal models of TBI and the cognitive and motor tasks that have been used in postinjury assessments in these models. With these categorizations in hand, we conducted a survey of the literature from the beginning of PubMed indexing to 31 March 2013, in order to objectively evaluate the range of functional assessments that exhibit prolonged deficits ( $\geq 1$ month) in various TBI models. We conducted ten PubMed searches with the following search terms: 'controlled cortical impact AND water maze', 'controlled cortical impact AND cognition', 'fluid percussion AND water maze', 'fluid percussion AND cognition', 'blast AND water maze', 'blast AND cognition', 'weight drop AND water maze', 'weight drop AND cognition', 'closed head injury AND water maze', and 'closed head injury AND cognition'. All papers matching these search terms were merged into one list.

Initially, 817 papers were found with these search terms, but results were then filtered for studies in rats or mice only (371 remained) that were not reviews (362 remained) and that included an uninjured/sham control group in comparison with an injured group in one or more functional assessments (45 papers were excluded). This filtering indicates that approximately $12 \%$ of rodent TBI papers did not include sham versus injury comparisons and resulted in a total of 314 unique papers for review.

\section{Injury models}

There are a wide range of injury paradigms used to model TBI in rodents. Broadly, these are typically divided into focal and diffuse injury models, although considerable pathological and functional overlap between the focal and diffuse models exists. Below, we briefly describe the main features of each model (Figure 1) [40]. 


\section{Fluid percussion injury models}

Fluid percussion injury (FPI) is the most commonly used model for studying TBI. First described in 1965, Lindgren and Rinder developed the fluid percussion model in rabbits [41]. In 1976, FPI was characterized by Sullivan et al. in cats [42], and finally by Dixon et al. in rats in 1987 [43]. Fluid percussion has also been adapted for swine [44,45] and mice [46]. FPI involves trephining a hole in the skull and cementing a plastic cap over the craniotomy. The FPI device has a saline-filled plexiglass cylindrical tube attached to the plastic cap via a Luer-Loc connection. A weighted pendulum swings down from a desired height and impacts the opposite end of the tube, starting a fluid wave that ends on the intact dura of the animal. The fluid wave impacts dura while also filling into interstitial spaces, causing both focal and diffuse brain injury. The craniotomy can be placed directly on top of the sagittal suture for a medial FPI (MFPI) [43], or can be placed lateral to midline for a lateral FPI (LFPI) [47]. Standard LFPI in rodents causes neuronal damage to the hilar region of the dentate gyrus [48], and the ipsilateral cortex, hippocampus and thalamus [49]. Small changes in the lateral, rostral or caudal location of the craniotomy for LFPI can have different effects on behavior and pathology [50,51]. LFPI also results in increased extracellular glutamate and aspartate, widespread reactive astrocytosis, cavity formation, blood-brain barrier disruption, ipsilateral cortical and subcortical hemorrhage, and cerebral edema [47,52-54].

\section{Controlled cortical impact model}

The controlled cortical impact (CCI) model of TBI employs a pneumatic impact device to drive a rigid impactor to deliver mechanical energy onto the exposed and intact dura mater. This mechanical energy causes a deformation of the brain. The advantage of this model is the reproducibility and precise control of the mechanical parameters: dwell time, velocity and depth of impact [40,55]. The first CCI was described in ferrets [56] and was later adapted for use in rats [57] and mice [58,59]. CCI has also been described in swine and monkeys [40]. The neuropathology induced by CCI includes contusion, subdural hematoma, subarachnoid hemorrhage, edema, hypoperfusion, neurodegeneration and cavitation $[57,60,61]$. While some diffuse damage also occurs, CCI is considered to induce focal brain injury. This kind of damage occurs proximal to the mechanical impact and induces brain injury of both cortical and subcortical structures and ventricular enlargement (Figure 2) [55].

\section{Weight drop impact-acceleration model/closed head injury}

The weight drop impact-acceleration (WDIA) model was developed by Marmarou in 1994 [62,63]. WDIA is a popular model for TBI, involving very inexpensive equipment and minimal invasiveness. A rodent is strapped onto a foam block after having a metal disk affixed to its skull. A weight is dropped from a desired height to directly strike the disc. This results in a diffuse injury with widespread axonal damage, while still keeping the cranium intact [63]. Subarrachnoid hemorrhage, rapid and transient blood-brain barrier disruption, and brain edema are observed following WDIA in rodents [63,64]. For more precise control and manipulation of diffuse injuries to a rodent's head without trephination, many investigators are developing experimental closed head injury (CHI) models utilizing CCI devices to directly strike a disk attached to the skull, or the head itself without any protection. These injuries produce very similar pathologies to WDIA but with increased reproducibility.

\section{Blast injury model}

The blast model of TBI has become an increasingly popular model to study in the laboratory owing to its ability to mimic blast waves associated with explosions. Blast or explosions are the most common cause of TBI to soldiers in Iraq [65], leading to long-term cognitive and emotional deficits. The blast injury model uses a long metal tube that is closed on one end. An air pressure wave or an explosion is used to deliver over- or under-pressure waves beginning at the closed end of the tube. Rodents are placed at the open end of the tube to receive the shockwave, affecting the whole body and the head [66]. Blast injuries result in neuronal damage in the temporal cortex, cingulate gyrus, piriform cortex, dentate gyrus and the CA1 region of the hippocampus [67].

\section{- Penetrating ballistic-like brain injury model}

Penetrating ballistic-like brain injury (PBBI) is considered a type of focal brain injury [40], even though there may also be diffuse damage. Firearm-related injuries are on the rise nationwide in the USA, with bullet wound injuries to the head being a common cause of PBBI-TBIrelated injuries. Williams et al. describe PBBI as a high-energy transfer wound that causes direct damage to the brain via formation of a temporal intracranial cavity $[68,69]$. The injury is produced 


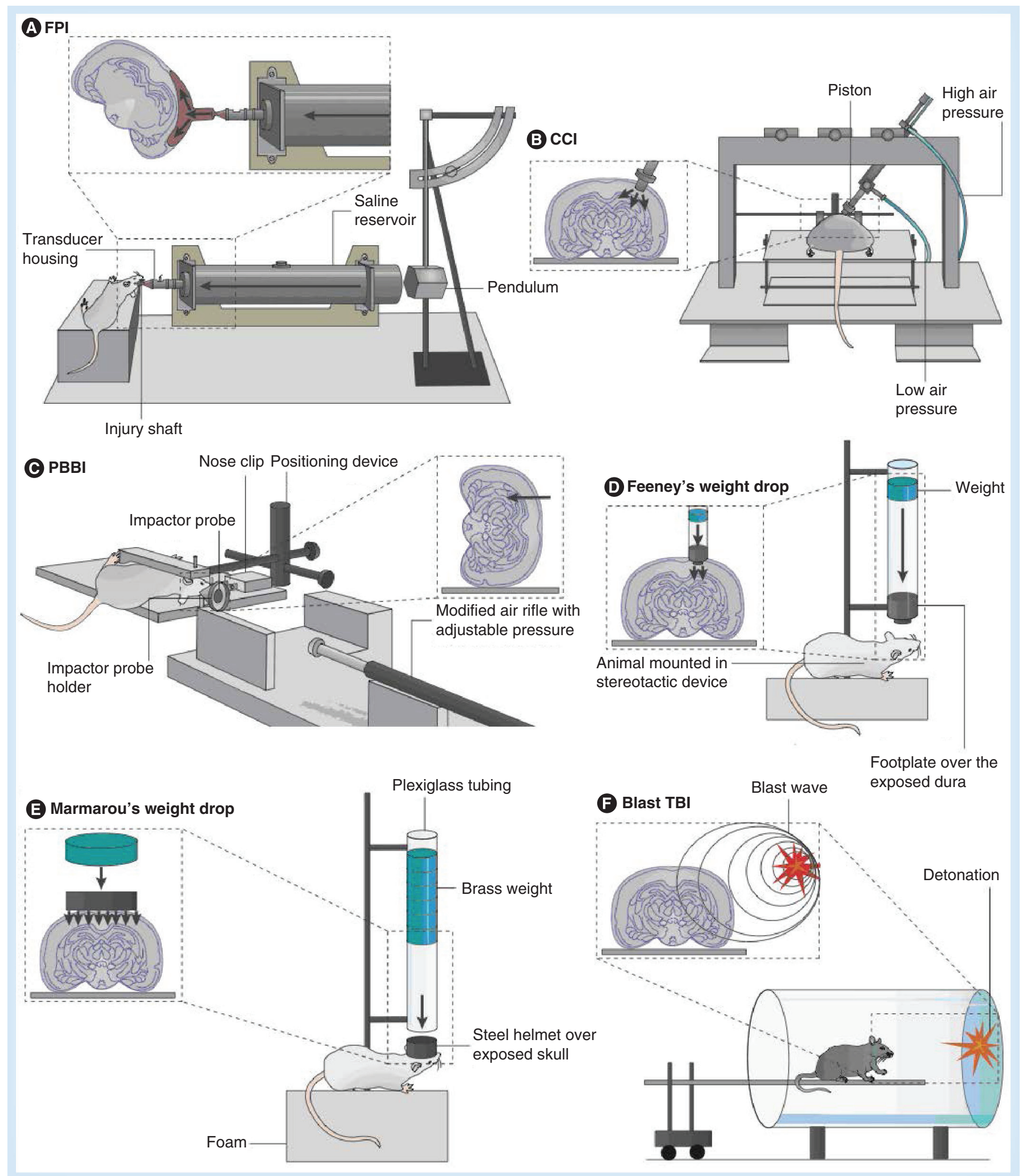

Figure 1. Five main models of traumatic brain injury in rodents. (A) FPI, (B) CCI, (C) PBBI, (D \& E) weight drop injuries (closed head or open) and (F) blast injury.

CCl: Controlled cortical impact; FBI: Fluid percussion injury; PPBI: Penetrating ballistic-like brain injury; TBI: Traumatic brain injury Reproduced with permission from [40]. 
by a specially designed probe inserted into the brain at the desired location, leaving a permanent injury tract, followed by a fast inflation of an attached balloon to mimic the temporary cavity provoked by a penetrating bullet [70]. The first penetrating brain injury was described in rhesus monkeys [71], and subsequently in cats [72] and rats [70]. PBBI results in intracerebral hemorrhage, brain edema, and degeneration of neurons and fiber tracts remote from the core lesion $[68,73,74]$. This model is relatively rare (only four papers were found matching the search criteria). Hence, the PBBI model was not analyzed further.

\section{- Instant rotational model}

A instant rotational model of traumatic injury was first developed by Gennarelli et al. in 1982 [75]. Primates were originally studied in this model, which involves quickly accelerating the animal's head in a given direction. In 1994, this model was also utilized to study TBI in swine [76]. The instant rotational model is limited to use in larger animals, as the inertial force required to cause damage is inversely related to brain size and is impractical for use in rodents. Hence, this model was not included in the set of papers in this review.

\section{Summary of TBI models}

While there are many different methods to model TBI in rodents, and each method has variations in its application, the most common models are the FPI, CCI and WDIA/CHI models. Overall, we found 140 FPI papers (either lateral or medial), that met our inclusion criteria, $130 \mathrm{CCI}$ papers, 24 WDIA papers, $15 \mathrm{CHI}$ papers and seven blast papers during our review of the literature from the inception of PubMed to the present (31 March 2013; Figure 3A).

\section{Assessments of functional outcome in rodents after TBI}

There are a host of functional outcome measures suitable for use in rodents. Functional recovery and post-TBI deficits can be assessed in a subject's global neurological performance, in a range of gross and fine motor tasks, on sensorimotor tasks, tests of pure sensory response, cognition (including long- and short-term memory, spacial memory, etc) and emotional responses. We describe each of these domains in order followed by an analysis of the number of papers reporting deficits in various domains at a minimum of 1 month postinjury, as defined by 28 days postinjury.

\section{Global assessments of general impairment}

Following TBI, a global assessment of the animals' neurological status is often conducted using a set of generalized neurological screening tasks. Such global assessments are used to verify injury severity, as inclusion/exclusion tests for assignment to treatment groups or as final end point measures. Currently, there are several neurological test/scoring protocols employed by different research groups in the brain trauma field.

\section{Neurological severity score}

One of the first global scoring systems was developed by Shapira et al. in 1988 [77] to measure the clinical relevance of a CHI rat model by determining a neurological severity score (NSS) based on an animal's response to a series

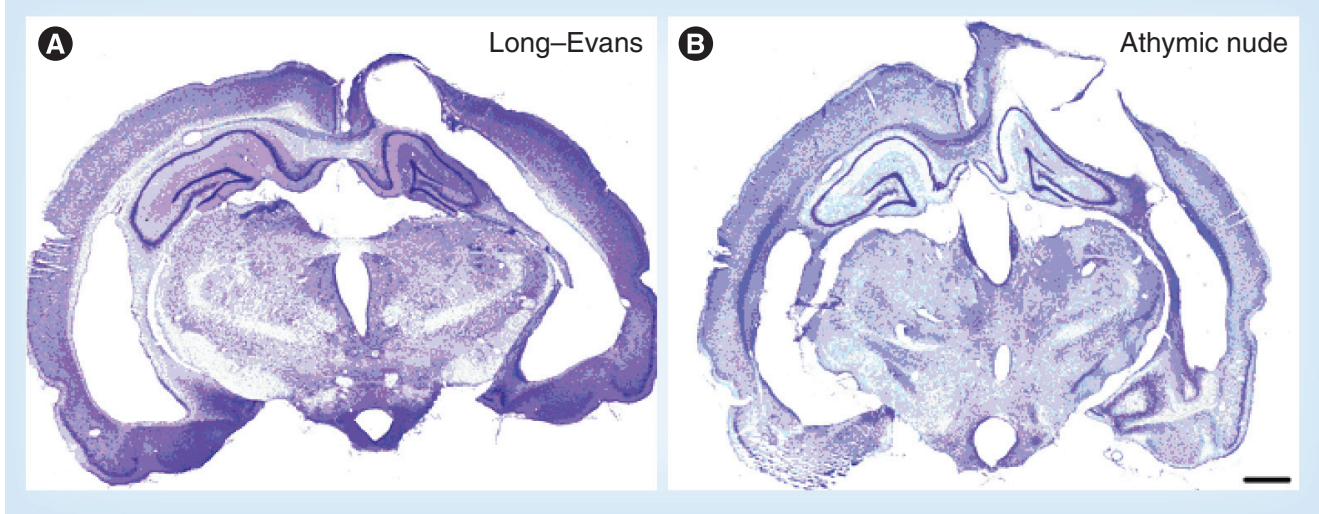

Figure 2. Nissl-stained rat brain sections of traumatic brain injuries induced by controlled cortical impact. (A) Long-Evans and (B) athymic nude rats display similar pathologies of cortical tissue loss and hippocampal damage at 22 weeks postinjury following a $2.00-\mathrm{mm}$ deep, $3.5-\mathrm{m} / \mathrm{s}$ impact using a TBI-0310 traumatic brain injury device (Precision Systems \& Instrumentation). Scale bar: $1 \mathrm{~mm}$. 

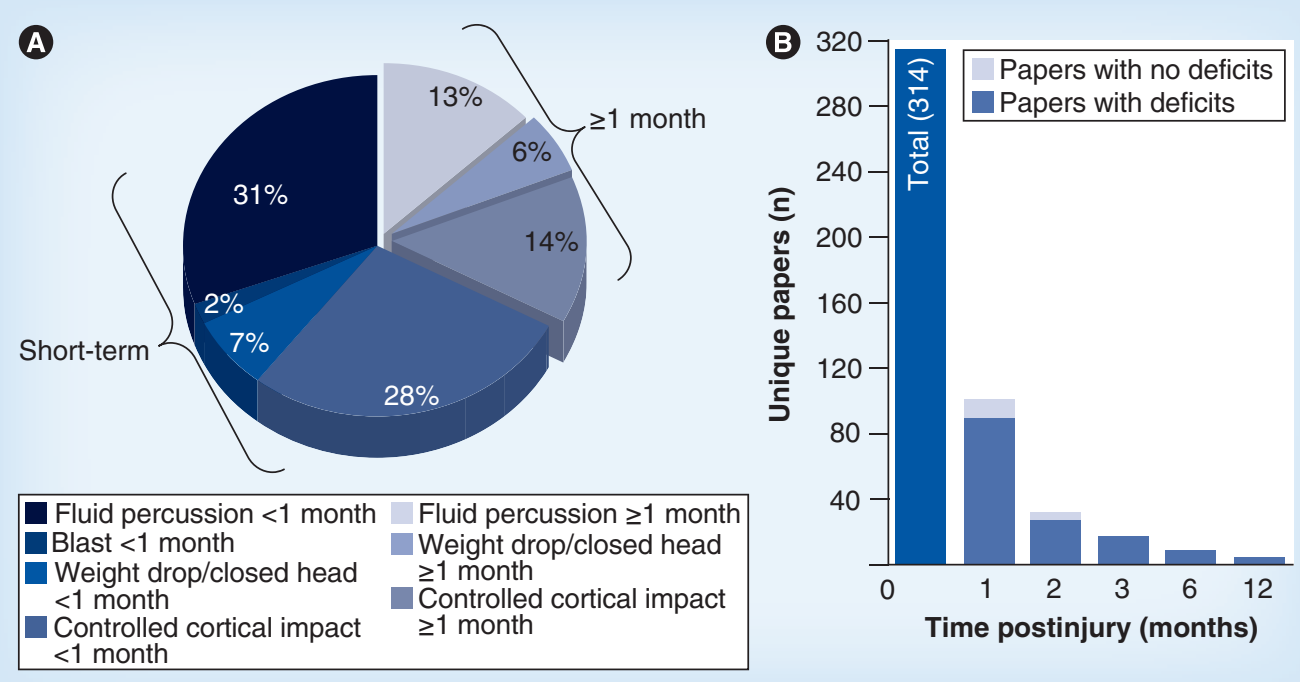

Figure 3. Comparison of rodent traumatic brain injury papers assessing short-term and long-term functional outcomes of different models of traumatic brain injury. (A) A total of 314 papers were reviewed that used either fluid percussion injury, weight drop impact-acceleration model/closed head injury, controlled cortical impact or blast models. Only $33 \%$ of the reviewed papers assessed functional outcomes at 1 month or more, and the majority of these were in fluid percussion injury models (41) or controlled cortical impact models (43). (B) An analysis of papers reporting longterm deficits in functional outcomes (dark blue bars) versus papers reporting no deficits (light blue bars) at 1, 2, 3, 6 and 12 months post-traumatic brain injury. Few papers assess long-term deficits in traumatic brain injury models. The first bar represents all papers reviewed $(n=314)$.

of simple tests post-TBI. Rodents were evaluated for their ability to exit a 50 -cm circle, for righting reflex, seeking behavior, hemiplegia or hemiparesis, with higher scores indicating more deficits. Increased NSS scores were correlated with damaged tissue pathology [77]. The NSS was expanded and refined by Shohami $e t$ al. in 1995 to include more reflex tasks [78]. Further adaptations to the NSS include a 14-point scale consisting of motor (muscle status and abnormal movement), sensory (visual, tactile and proprioceptive) and reflex tasks [79,80], which became the basis for the modified NSS (mNSS).

\section{Modified neurological severity score}

The mNSS is a global assessment of function gauged by a composite of motor, sensory, balance and reflex tasks [79,81]. The mNSS is based on the NSS (as adapted from [77] by [78]) as well as incorporating additional tasks that target motor function [82-84], sensory function [85], balance [86] and reflex function $[84,86,87]$ on a scale of 1-14 points in mice [88]. The mNSS is frequently used to evaluate long-term neurological function after unilateral TBI in rodents [89-94]. While the current mNSS was originally designed using mice [88], there is a trend of including balance beam tasks as part of the mNSS when evaluating rats [81,89-91,95]. However, the 'mouse' mNSS has been used for global assessments in rats as well [96]. The mNSS as modified for rats consists of an 18-point deficit score, where a composite score of $\leq 6$ designates a mild TBI, 7-12 designates moderate TBI and $\geq 13$ designates severe TBI. In a unilateral model of TBI, a high score in the motor portion of the mNSS indicates asymmetric behavior due to contralateral limb paralysis related to damage to the cerebral cortex; a high score in the sensory tasks of the mNSS is indicative of damage to the cerebral cortex and corticospinal pathways (which overlaps with motor deficits); a high score in balance portion indicates damage to the pons and mesencephalon; a high score in the reflex portion of the mNSS indicates damage to the medulla, pons and upper cervical cord [79,97].

\section{Composite neuroscore}

The composite neuroscore originates from a scale designed by McIntosh et al. [47,98]. The composite neuroscore initially consisted of five tests: forelimb flexion upon suspension by the tail; decreased resistance to lateral pulsion; circling behavior upon spontaneous ambulation; the angle board task, which tests the animal's ability to stand on an inclined angle board; and the grip test, which requires the animal to use its four paws and tail to remain on a narrow, $2-\mathrm{cm}$ wide wooden beam [98]. The five tasks are combined for a possible score of 20 points [47,98]. A composite neuroscore of 20 would indicate a normal animal; 15 indicates slight 
motor impairment; 10 indicates moderate motor impairment; 5 indicates a severely impaired animal; and 0 indicates an afunctional animal. This set of criteria was then modified and expanded to seven tasks with a maximum score of 28 [99]. The seven task composite neuroscore is employed by various groups to detect long-term neurological deficits [100-102], although variations of the task composition and/or scoring approaches have also been used [43,103-106].

Overall, 14\% (45 of 314) of the articles in this review contained a global neurological assessment as part of their functional analysis. Of these, 23 assessed a global neurological assessment using LFPI, 14 using CCI, four using WDIA and four using CHI. Studies that looked for deficits at 1 month or more include ten using LFPI, six using CCI and four using CHI. Deficits in a global neurological assessment in TBI rodents compared with uninjured controls at 1 month postinjury were observed in nine papers using LFPI [100,102,107-113] and six using CCI [90,91,93,114-116]. TBI papers that detected sustained neurological deficits $\geq 1$ month postinjury via global neurological assessment of function account for less than $5 \%$ of the total number of articles reviewed (15 of 315).

The global assessments used in the papers using CCI were relatively uniform in protocol and application among researchers using the mNSS. A common element of the CCI papers reviewed that found deficits at 1 month postinjury, is that six of the seven articles were conducted using common parameters: 300-400 g, male Wistar rats (six to eight per group), a moderate CCI injury (2.5 $\mathrm{mm}$ deep, $4 \mathrm{~m} / \mathrm{s}$ ) over the left cortex, mNSS analysis and a maximum assessed time point of 35 days postinjury $[89,90,92,93,116,117]$. However, global assessment protocols used in papers using FPI more often used a composite neuroscore, which had more variation in individual components and scoring $[100-102,108,110]$. One concern regarding the validity of any global assessment is the reproducibility and subjectivity of human scoring, as opposed to more objective measurements. In early TBI articles reviewed, reproducibility was often supported through confirmation of inter-rater reliability [47,98].

\section{Motor assessments}

Motor behavior tasks can be divided into many categories but within the papers reviewed, two main categories emerge. The first category is gross motor behavior, which includes walking, running and torso movements; these movements typically use large muscle groups. Tasks that are included in gross locomotor behavior are balance beam, beam walking, foot fault, grip test, inclined plane, open field, righting reflex, rotarod, rotating pole and the swim-speed component of the Morris water maze (MWM). The second category of motor behavior tasks is fine motor behaviors, which use smaller muscles such as muscles in the paws. From the papers reviewed beam walking, bilateral tactile adhesive task and the cylinder task were used as tasks assessing fine motor control. Of course, it is difficult to separate out tasks that are purely motor or purely sensory. Tasks that are sensorimotor in nature are included in this motor section, whereas pure sensory tasks are in a separate section.

\section{Balance beam}

Balance beam is a test for motor and vestibular function. Most papers describe this as a motor function task; however, some emphasize the task's sensory assessment. Balance beam involves an elevated narrow beam, which the animal needs to balance on; the latency for the animal to fall off the beam is recorded (typically with a maximum latency of $60 \mathrm{~s}$ ). A round or narrower beam can be used to increase the difficulty of the task. The neuroanatomy that is reported to be involved in balance beam is the motor cortex [118] and possibly cerebellum [119,120]. Of all papers reviewed, 43 assessed balance beam using CCI, nine using LFPI, seven using MFPI, three using CHI and two using WDIA. Studies looking at deficits at 1 month postinjury or later include one using CCI and one using LFPI. Deficits in balance beam performance in TBI rodents compared with uninjured controls at 1 month postinjury were observed in one paper using CCI [121] and one using LFPI [113].

\section{Beam walking}

Similar to balance beam, beam walking is a fine motor coordination task for rodents that uses a negative reinforcement paradigm. Animals must escape from ambient light and/or high-decibel white noise by crossing an elevated narrow beam and entering a dark goal box on the other end of the beam. The time that it takes an animal to cross the beam and the number of foot slips it makes while crossing are recorded. Beams are generally placed $3 \mathrm{~m}$ above the ground so that the animal is fearful from the height. Foot slips and latency to reach the goal are measured during this task. Scoring ranges from one to seven, with one being unable to traverse the beam and unable to place the affected limb on the horizontal 
surface, and seven being the animal was able to traverse the beam normally with no more than two foot slips. Regions of the brain that may affect this performance in this task are the motor cortex, sensory cortex, thalamus, brain stem and cerebellum [122,123]. Of all papers reviewed, 36 assessed beam walking using CCI, 25 using LFPI, eight using MFPI, two using WDIA, one using CHI and one using blast. Studies looking at deficits at 1 month postinjury or later include nine using LFPI, seven using CCI and one using WDIA. Deficits in beam walking performance in TBI rodents compared with uninjured controls at 1 month postinjury were observed in six papers using CCI [116,124-128], four using LFPI $[122,123,129,130]$, one using repeated LFPI [131] and one using WDIA [122].

\section{Bilateral tactile adhesive removal task}

The bilateral tactile adhesive removal task involves placing small rectangular patches of adhesive bracelets onto a rodent. These bracelets are wrapped above the front paws and the time taken for removal from both forelimbs is recorded. This task measures sensorimotor deficits in the caudal forelimb region, rostral forelimb region and anteromedial cortex of the brain [132]. Of all papers reviewed, four assessed the bilateral tactile adhesive removal test using CCI, three using LFPI and one using WDIA. Studies looking at deficits at 1 month postinjury or later included three using LFPI and two using CCI. Deficits in the bilateral tactile adhesive removal task in TBI rodents compared with uninjured controls at 1 month postinjury were observed in one paper using LFPI [111] and one using CCI [133].

\section{Cylinder test}

The cylinder test is used to assess asymmetries in forelimb function. An animal is placed in a cylinder and the number of times it places its contralateral, ipsilateral or both paws on the wall of the cylinder during rearing are counted. Injured animals will often not use their contralateral limbs to balance themselves while rearing along the walls of the cylinder $[134,135]$. Structures suggested to be involved in the cylinder test are midbrain median raphe and dorsal raphe nuclei [136]. Of all papers reviewed, two assessed the cylinder test using CCI and one using LFPI. Studies looking for deficits at 1 month or later include one using CCI [134] and one using LFPI [136], both of which observed deficits in TBI rodents compared with uninjured controls.

\section{Foot fault}

Foot fault or locomotor placement tasks utilize a wire grid to examine the number of times individual paws slip through the grid during a preset number of paw placements. Increases in foot faults might be due to tissue loss in the cortex, striatum and corticostriatal connections [137]. Of all papers reviewed, 12 assessed the foot fault task using CCI, five using LFPI, two using CHI and one using WDIA. Studies looking at deficits at 1 month postinjury or later include eight using CCI and one using LFPI. Deficits in foot fault performance in TBI rodents compared with uninjured controls at 1 month postinjury were observed in seven papers using CCI $[89,90,93,94,133,138,139]$ and one using LFPI [110].

\section{Forelimb flexion}

Forelimb flexion is an assessment of neurological function examining flexion or adduction of an animal's forelimbs after lifting the animal by its tail. The amount of flexion an animal exhibits is graded on a scale of $1-4$, with complete adduction as 1 and the normal lack of adduction as 4. Of all papers reviewed, four assessed forelimb flexion using CCI and three using LFPI. Studies looking at deficits at 1 month postinjury or later included three using CCI. No deficits in forelimb flexion in TBI rodents compared with uninjured controls at 1 month postinjury were observed in any paper.

\section{Inclined plane}

The inclined plane test is a sensorimotor task where rodents climb an inclined plane at varying degrees of difficulty. Animals are placed perpendicular to the downward slope of an inclined plane. The inclination when animals lose their footing is recorded. There are several additional parameters that can be measured, including first fall angle, threshold angle, total falls for inclined plane and best, mean and median latencies to finish the task. Anatomy that may be involved in the inclined plane task are cortical and subcortical regions, as well as white matter tracts, especially those found in the brainstem and cerebellum [122]. Of all papers reviewed, three assessed the inclined plane test using LFPI, three using WDIA and two using CCI. Studies looking at deficits at 1 month postinjury or later include one using LFPI and one using WDIA. Deficits in the inclined plane task in TBI rodents compared with uninjured controls at 1 month postinjury were observed in one paper using LFPI [122]. 
Limb-placing function

Limb-placing function is an assessment to detect tactile and proprioceptive deficits postinjury. Animals are held in the experimenter's hand, taking care not to stimulate the face. Forward and sideways placing is tested by lightly touching the edge of a table with the lateral or dorsal edge of a paw, which stimulates the animal to place the paw down and push against the table edge. The limb of the animal that is contralateral or ipsilateral to the injury is also gently pulled away from the body and the placement after release is recorded. Animals are given a score from 0 (no limb placement) to 2 (immediate and complete placing for each limb). This motor task is used to detect damage in the frontal and parietal cortex area of the brain [140]. Only one LFPI injury paper used limb placing as a measure of motor deficit, but prior to 1 month postinjury.

\section{MWM - swim speed}

Swim speed during the MWM is one of many measurements that can be obtained from the water maze task; while swim speed is a motor based score, it is discussed with the other MWM tasks that are more cognitive (see below).

\section{Open-field}

Open-field assessments are conducted in an open field, typically a square or round opentopped box. Animals are allowed to freely explore the arena for 5 mins and movements are recorded either by a visual tracking system or hand-scored. Possible outcome measures recorded are: time spent in the center of the area; total distance traveled; speed; and number of rearings [128,141,142]. These behaviors can be affected by damage to the prefrontal cortex [141]. Of all papers reviewed, nine assessed the open-field performance using CCI, four using WDIA, three using LFPI, two using CHI and one using blast. Studies looking at deficits at 1 month postinjury or later include three using LFPI and two using WDIA. Deficits in openfield behavior in TBI rodents compared with uninjured controls at 1 month postinjury were observed in two papers using WDIA [143,144].

\section{Rotarod}

Rotarod is a considered a sensitive measure for integrated motor abilities by requiring animals to maintain balance on a rotating rod [145]. The amount of time spent balanced on the rotarod before falling off or gripping the rod itself and spinning around once is measured. Of all papers reviewed, 14 assessed rotarod using CCI, six using LFPI, five using CHI, three using MFPI, two using WDIA and one using blast. Studies looking at deficits at 1 month postinjury or later include six using CCI, two using LFPI, two using WDIA and two using CHI. Deficits in rotarod performance in TBI rodents compared with uninjured controls at 1 month postinjury were observed in two papers using CCI [146,147], two papers using WDIA [143,144], one using LFPI [111] and one using repeated $\mathrm{CHI}$ [148].

\section{Rotating pole}

The rotating pole task primarily tests motor coordination. The rotating pole is a wooden pole with platforms on each end. The animal is expected to cross from one platform to the other while the pole is rotating [149]. The pole rotations generally change directions three- to ten-times per minute. Scores from 0 to 6 are given based on an animal's ability to cross without falling, while also taking into account the number of foot slips. Of all papers reviewed, four assessed the rotating pole test using LFPI and two using CHI. Studies looking at deficits at 1 month postinjury or later include two using LFPI and two using CHI. Deficits in the rotating pole task in TBI rodents compared with uninjured controls at 1 month postinjury were reported in two papers using LFPI $[102,113]$ and one using repeated $\mathrm{CHI}$ [148].

\section{Wire grip test}

The wire grip test is performed by suspending a wire between two poles and allowing the animal to hang on the wire. Functional performance is assessed by grading the degree of attachment and movement of the animal. Typical scoring of this task is: 0 , fell from wire within 30 seconds; 1, unilateral grasp of either upper or lower extremities; 2, midline grasp of both upper and lower extremities but not tail; 3 , midline grasp of all extremities plus tail; 4, movement along the wire after achieving a score of 3 ; and 5 , climbing to and down one of the poles within 60 seconds [150]. Of all papers reviewed, 12 assessed the wire grip test using CCI and two using WDIA. None of these studies looked at deficits at 1 month postinjury or later.

\section{- Sensory assessments}

\section{Acoustic startle response}

Acoustic startle response and prepulse inhibition are generally tested together. In standard acoustic startle response a loud noise is presented, causing a flinching response from the rodent. While this test assesses auditory function, motor 
and emotional components are also involved in the flinching reflex. Prepulse inhibition is a more sensitive measurement of auditory function. When presenting a prepulse of lower decibels, it inhibits the response to a louder pulse [142]. One paper using CCI and one paper using blast utilized the acoustic startle task, but neither assessed startle response after 1 month postinjury.

\section{Gap cross test}

Rats can be trained to jump across gaps in the dark and considerably larger gaps in the light for a food reward [151]. In the dark they use their vibrissae at greater distances. Animals are typically trained to jump 2-cm gaps initially, then incrementally increasing the distance. Barrelfield lesions and trimming of whiskers has been shown to decrease performance of gap crossing [151]. Out of all the TBI papers reviewed, none used the gap cross test as a behavioral task.

\section{Whisker nuisance task}

Whisker nuisance task is a sensory task [151]. During this sensory task, whiskers are stimulated using a wooden applicator for periods of 5 mins for three different periods of time. Recordings of subjects' responses are analyzed for posture, grooming, evading, whisker position and general response to the applicator. Abnormal responses are scored by the experimenter. Of all the TBI papers reviewed, none used the whisker nuisance task.

\section{Cognitive assessments}

One of the most common and debilitating features of TBI is alterations in cognition, including confusion, memory impairments and deficits in executive function. There are a variety of tests in rodents that assess cognitive function. Deficits using these tasks could suggest that there is damage in the hippocampus and other brain structures involved in learning and memory.

\section{Barnes maze}

The Barnes maze is a cognitive test of spatial learning and memory [152]. Rodents are placed on a circular board raised several feet from the ground. Holes lining the entire perimeter of the board allow the rodents to look through and explore what is below. One hole on the board contains a dark, escape compartment below. Rodents are trained over several days to learn the location of this compartment. Latency to find the compartment is used as a measurement of spatial learning. By moving the location of the box during training, the task can assess working memory. Of all papers reviewed, four assessed Barnes maze performance using CCI, three using LFPI and two using WDIA. Two studies looked at deficits at 1 month postinjury using WDIA. Deficits in Barnes maze performance in TBI rodents compared with uninjured controls at 1 month postinjury were observed in two papers using WDIA [143,144].

\section{Fear conditioning}

Fear conditioning is used as a measure of associative learning of a presented cue (often a tone or light) with a subsequently presented stimuli, most often a foot shock [153]. Training includes a single day of tone-shock pairings. Testing occurs the following day to the context or to the cue in a novel context. Animals having learned the association will freeze upon being placed into the context or to the cue. The hippocampus is involved, mostly in contextual fear conditioning, while the amygdala is involved in cued fear conditioning. Of all papers reviewed, three assessed contextual fear conditioning using using LFPI, two using CCI and two using CHI. Studies looking at deficits at 1 month postinjury or later include one using LFPI and one using CCI. Neither of these studies found deficits after 1 month. Of all papers reviewed two papers assessed cued fear conditioning using CCI and one using LFPI. Studies looking at deficits at 1 month postinjury or later include one using CCI and one using LFPI. Neither of these studies found deficits after 1 month.

\section{Morris water maze}

In 1984, Morris developed the MWM task [154]. The MWM is primarily a cognitive assessment of spatial learning and memory. Rodents are placed into a large tank filled with water to find a platform hidden below the surface of the water. They use distal cues in the testing room to find the platform [154,155]. The animals are tested individually and placed into different starting positions of the tank (north, south, west, east, northwest, southwest, southeast or northeast). Spatial learning is evaluated with repeated trials to locate the hidden platform. Spatial learning refers to the process through which animals encode information about their environment to facilitate navigation through space and recall the location of motivationally relevant stimuli. The animal must learn to use distal cues to navigate and find a hidden platform [155]. Reference memory is subsequently evaluated by removing the platform. The rodent's time spent searching the 
space where the platform used to be is used as a measure of its reference memory [155]. Reference memory represents knowledge of aspects of a task that remains constant between trials. It is a long-term memory that can last for days, weeks, months and years [156]. This memory is evaluated at the end of learning, commonly by use of a probe trial $24 \mathrm{~h}$ after the last acquisition day. Reversal learning of the MWM is a modification of the original testing protocol in which the platform is relocated to another quadrant (commonly in the opposite quadrant) and another four testing trials are administered for an additional 5 days, after already learning the initial location of the platform. This tests whether or not animals can extinguish their initial learning of the platform's position and acquire the new platform position [155]. Another variation of MWM is to test for working memory, or shortterm memory. The term short-term memory implies a repository; a place for the temporary storage of facts [156]. To test this memory, the platform is relocated every day during several days of testing. Specific deficits in MWM testing have been found in animals with damage in hippocampus, striatum, basal forebrain, cerebellum and neocortex (prefrontal cortex, insular cortex, entorhinal and perirhinal cortex) [157].

While there are many variations of the MWM protocol and specialized subtests, the five MWM components most commonly used in the TBI field include: learning latency; probe trial; working memory; reversal; and swim speed. We discuss each separately below.

\section{Learning latency (spatial learning)}

The most common outcome measure when using the MWM is the time it takes the subject to locate the hidden platform. Learning latency is often referred to as escape latency. Of all papers reviewed, 107 assessed learning latency using CCI, 97 using LFPI, 19 using WDIA, 18 using MFPI, 17 using CHI and three using blast. Studies looking at deficits at 1 month postinjury or later include 29 using LFPI, 28 using CCI, seven using CHI, six using WDIA and two using MFPI. Deficits to find the platform in TBI rodents compared with uninjured controls at 1 month postinjury were observed in 22 papers using LFPI [100-102,107,109-113,129,136,158-168], 21 papers from CCI [91,93,114,116,121,125,134,147,169-181], four using WDIA [182-185], three using CHI [186-188], two using repeated LFPI [131,189], one paper MFPI [190], one using repeated WDIA [191] and one using repeated CHI [192].

\section{Probe (reference memory)}

In the probe test, the platform is removed and the rodent is allowed to search for the platform. Most commonly, time spent in the target quadrant, or in the platform zone, is measured. Of all papers reviewed, 43 assess the probe test using LFPI, 33 using CCI, nine using WDIA, seven using $\mathrm{CHI}$, two using MFPI and one using blast. Studies looking at deficits at 1 month postinjury or later include 13 using LFPI, 11 using CCI, four using WDIA, four using CHI and two using MFPI. Deficits in probe trial performance in TBI rodents compared with uninjured controls at 1 month postinjury were observed in eight using LFPI [100,109,110,161,163,164,193,194], six using CCI [89,171,174-176,181], three using WDIA [182-184], two using MFPI [195,196] and two using CHI [186,187].

\section{Working memory (short-term memory)}

Of all papers reviewed, five assessed the working memory task of MWM using CCI, two using LFPI and one using CHI. Only one study looked at deficits at 1 month postinjury or later, which did see deficits using a LFPI [136].

\section{Reversal learning}

Of all papers reviewed, seven assessed reversal learning test using LFPI and one using CCI. Studies looking at deficits at 1 month postinjury or later include six using LFPI. Deficits in reversal learning in TBI rodents compared with uninjured controls at 1 month postinjury were observed in two papers using repeated LFPI [131,189] and one paper using LFPI [164].

\section{Swim speed (motor)}

The MWM swim speed is one of many measurements that can be obtained from the water maze task. Swim speed is the distance covered in the water maze over how long it took the animal to find the hidden platform. This is an important measure for motor function (not cognition) because if there is no difference in swim distance but a difference in time to reach platform, it could suggest that there is a motor deficit. Of all papers reviewed, 43 assessed MWM swim speed using LFPI, 31 using CCI, ten using WDIA, eight using CHI, two using MFPI and two using blast. Studies looking at deficits at 1 month postinjury or later include 14 using LFPI, seven using CCI, four using CHI, three using WDIA and one using MFPI. Deficits in MWM swim speed in TBI rodents compared with uninjured controls at 1 month postinjury were observed in two papers using LFPI [100,163] and one using repeated LFPI [189]. 


\section{Other}

There are several other variants or subtasks that can be assessed during the MWM, including computation of a 'memory score', measurement of the total distance traveled, using a visible platform rather than a submerged one, calculating the percentage of time animals spend in the 'correct' quadrant or counting the number of platform crossings. However, these alternative measures are not commonly used and are not as uniform as the five MWM tests reviewed above.

\section{Novel object recognition}

Novel object recognition (NOR) evaluates nonspatial hippocampal-mediated memory. Animals are allowed to explore two identical objects in a chamber for a predetermined amount of time and then, after an intertrial interval, are placed back into the chamber with one familiar object and one novel object. The times spent with the novel and familiar objects are recorded. Control animals will spend more time exploring the novel object. Brain structures implicated in this task are the dentate gyrus, the CA1 and CA3 regions of the hippocampus [128], and the perirhinal cortex [197]. Of all papers reviewed, three assessed NOR performance using CCI and one using WDIA. Studies looking at deficits at 1 month postinjury or later include one using CCI and one using WDIA. Deficits in NOR performance in TBI rodents compared with uninjured controls at 1 month postinjury were observed in one paper using WDIA [198].

\section{Novel place recognition}

Novel place recognition evaluates spatial hippocampal-mediated memory. Animals are allowed to explore two identical objects in a chamber for a predetermined amount of time and then, after an intertrial interval, are placed back into the chamber with two identical objects, but one has been moved to a new location. Control animals will spend more time exploring the object in the new location. In this review no papers used this task as a measure for TBI deficits.

\section{Passive avoidance}

The passive avoidance task is used to assess simple nonspatial learning. Animals are placed into a lit chamber and a door opens to an adjoining dark chamber. Once the animal crosses to the dark chamber, the door closes and the animal receives a mild foot shock. The animals are tested the following day and the latency to cross over to the dark chamber is recorded. Structures thought to be involved in this behavior are the nucleus basalis, amygdala, nucleus accumbens and, to an extent, the frontal cortex [199]. Of all papers reviewed, three assessed passive avoidance performance using WDIA, one using CCI, one using MFPI and one using blast. Studies looking at deficits at 1 month postinjury or later include three using WDIA and one using CCI. Deficits in passive avoidance performance in TBI rodents compared with uninjured controls at 1 month postinjury were observed in three papers using WDIA [200-202] and one using CCI [128].

\section{Radial arm maze}

Radial arm maze is a measure of spatial learning and memory. Food-restricted rodents navigate an eight- or 12-armed maze using spatial cues on the walls of the testing room, exploring each arm for food reinforcements. After several days to weeks of training, assessments can be made to see how well the rodent systematically goes down each arm looking for food. Performance is assessed by counting the number of errors or times a rodent goes down an arm they have already gone down. Brain structures that may be involved in this task are the hippocampus and the nucleus accumbens [203]. Of all papers reviewed, three assessed radial arm maze performance using LFPI and two using WDIA. Studies looking at deficits at 1 month postinjury or later include two using LFPI and one using WDIA. Deficits in radial arm maze performance in TBI rodents compared with uninjured controls at 1 month postinjury were observed in one paper using LFPI [122] and one using WDIA [122].

\section{Y-maze}

The Y-maze task is a hippocampal-based task that measures working memory $[204,205]$. The apparatus of the Y-maze is composed of three arms of equal length with a central entry zone. This task can either be assessed as a single-trial $[175,204,205]$ or a two-trial [202] task. In the singletrial task, an animal is allowed to explore for 5 mins and the time spent in each arm, number of arm entries and the order of arm entries are recorded, where a normal animal should explore all arms equally owing to spontaneous exploration. In the two-trial Y-maze one arm is blocked during the first trial and then all arms are open during the second trial. The time spent and entries into each arm are recorded. Of all papers reviewed, four assessed Y-maze performance using CCI, two using WDIA and one using 
CHI. Studies looking at deficits at 1 month postinjury or later include two using CCI, two using WDIA and one using CHI. Deficits in Y-maze performance in TBI rodents compared with uninjured controls at 1 month postinjury were observed in one paper using CCI [175], one using WDIA [206] and one using CHI [202].

\section{Emotional assessments Active avoidance}

The active avoidance task is a fear-motivated associative avoidance test that uses an electrical shock as negative reinforcement. In this task the animal has to learn to move from the dark chamber to the light chamber when a cue is presented. The number of crossings into the light chamber after the cue presentation, freezing and the latency for the animal to cross to the other nonshocking chamber are recorded. Structures thought to be involved in this behavior are the prefrontal cortex and the amygdala [207]. Of all papers reviewed, two assessed active avoidance performance using blast and one using WDIA. No papers assessed active avoidance at 1 month postinjury or later.

\section{Elevated plus maze}

The elevated plus maze is a task that assesses anxiety. The maze itself is cross-shaped, with two open arms and two closed arms. Rodents have a preference for dark places; therefore, behavior differences are assessed by the time spent in the closed arms of the maze relative to the open arms. Animals are placed in the center of the maze facing an open arm and tracked using motion detection software. The number of entries, time spent in each arm (open vs closed) and distance traveled are typically measured. Of all papers reviewed, five assessed elevated plus maze performance using LFPI, four using CCI and two using WDIA models. Studies looking at deficits at 1 month postinjury or later include five using LFPI and two using WDIA. Differences in anxiety between TBI rodents compared with uninjured controls at 1 month postinjury were observed in two papers using repeated LFPI [131,189], one paper using LFPI [129] and one using WDIA [202].

\section{Forced swim task}

Depression-like behavior can be assessed using the forced swim task [142]. This task typically uses a large beaker filled with water for the animals to swim in. There is no escape and trials last $<10 \mathrm{~min}$. Depression-like behavior is observed when the animal floats and is immobile. Of all papers reviewed, three assessed forced swim task performance using LFPI, two using WDIA and one using CCI. Studies looking at deficits at 1 month postinjury or later include three using LFPI and two using WDIA. Deficits in forced swim task performance in TBI rodents compared with uninjured controls at 1 month postinjury were observed in two papers using WDIA [200,201] and one paper using LFPI [189].

\section{Tail suspension test}

Depression-like behavior is assessed using the tail suspension test [208]. Rodents are hung from their tails in an isolation chamber for a given time period. Depression-like behavior is seen when the animals cease to right themselves. Immobility can be measured using tracking software or by scoring immobility by hand. More depressive behavior is observed when an animal is more immobile than the control group [142]. One paper using CCI used the tail suspension test [142], but not after 1 month postinjury.

\section{Analysis}

\section{- Numerical summary}

In total, 314 unique papers were reviewed, of which 101 (32\%) conducted a functional test at, or after, 1 month postinjury, where 43 used CCI, 41 used fluid percussion, 12 used weight drop and six used CHI (one used both LFPI and WDIA; Figure 3A). Of these 101 papers assessing function at $\geq 1$ month post-TBI, 88 papers (87\%) demonstrated deficits in one or more a functional outcomes (35 CCI, 35 FPI, 12 WDIA and six CHI [one used both LFPI and WDIA]; Figure 3B). Since we have suggested that even a 1 month assessment may not be sufficient time to allow for integration of hNSCs with the host, we also evaluated the number of papers that assessed function at 2, 3,6 and 12 months post-TBI. Combining papers using any injury model and any functional assessment demonstrating sustained deficits, we found 27 papers (9\%), 17 papers $(5 \%)$, eight papers $(2.5 \%)$ and four papers $(1 \%)$ at these respectively longer time points post-TBI exhibited deficits on one or more tasks (Figure 3B).

The most commonly used functional assessment was learning latency on the MWM (261 papers), a measure of cognitive function. The next most common functional assessments were MWM - swim speed (96 papers), MWM - probe test (95 papers), beam walking (73 papers), balance beam (64 papers), global neurological assessment ( 45 papers), and rotarod (31 papers; TABLE 1). 
Less than $33 \%$ of papers reviewed performed functional assessments at 1 month postinjury or later (101 of 314). The most common assessments used at 1 month or more after injury were MWM - learning latency (72 papers), MWM - probe test (34 papers), MWM - swim speed (29 papers), Global Neurological Assessment (20 papers), beam walking (17 papers), rotarod (12 papers), foot fault (nine papers), elevated plus maze (seven papers) and MWM - reversal (six papers).

The ten most common functional tasks used in two or more studies where deficits were observed at 1 month or greater postinjury (demonstrating replication of a sustained deficit), ranked by the number of papers demonstrating a deficit, include (where percentage indicates how many showed deficits): MWM - learning latency (76\%), MWM - probe (62\%), Global Neurological Assessment (75\%), beam walking $(71 \%)$, foot fault (89\%), rotarod $(50 \%)$, MWM - \% in correct quadrant (100\%), elevated plus maze (57\%), passive avoidance $(100 \%)$ and water maze - swim speed (10\%) (TABLE 2).

\section{Survival \& proliferation of human stem cells in rodent models of TBI}

In 'Criteria for predictive models of TBI \& assessment of stem cell therapies', we proposed two criteria necessary to fully evaluate therapeutic success of human stem cell transplantation strategies in preclinical animal studies of TBI. First and foremost, for the safety/efficacy of transplanted cells to be appropriately evaluated, survival and/or proliferation potential of transplanted cells must be maximized for the duration of the study [37]. We define 'survival' in relation to the initial dose and without respect to whether nearly all of the initial dose died off and only a small subset of the initial cells proliferated extensively, or whether all cells survived the transplant and only double once - as very few studies actually investigate the dynamics of such proliferation. In this context, if 50,000 cells were transplanted initially and upon sacrifice, 100,000 human cells were quantified stereologically, this would be reported as $200 \%$ cell survival.

Second, to evaluate therapeutic potential, there needs to be sufficient time for engrafted cell integration to effect functional outcome. Long-term cell survival is particularly difficult to achieve in preclinical in vivo studies, and hNSCs require more time to differentiate than rodent NSCs. Furthermore, both xenogenic and allogeneic transplantation require robust attenuation of immunorejection mechanisms in order to achieve good cell engraftment, either in the form of pharmacological immunosuppression of $\mathrm{T}$ cells, or constitutive suppression of $\mathrm{T}$ cells by virtue of immunodeficient rodents. In this regard, it is not surprising that the highest reported human cell survival in a rodent TBI model is only $21 \%$ of the initial transplantation dose [209], as this study used immunosufficient animals and no immunosuppression. The majority of human cell transplant studies into TBI models report cell survival under $10 \%$ or do not report on cell survival quantitatively at all. A total of 26 of 31 papers (84\%) transplanting a human cell population in a rodent TBI model do not report on cell survival (Table 3). Similar low xenografted cell survival rates in the CNS (averaging 17\% of the initial dose) have been reported in a recent review by Anderson et al. across multiple different traumatic injury types in which human cells were transplanted into immunocompetent animal models receiving immunosuppressive drug treatment [37].

Pharmacological, but combinatorial, immunosuppression may be an alternative approach to the use of immunodeficient animals. In some cases, for example, in immunocompetent C57BL/6 mice transplanted with hNSCs following spinal cord injury, FK506 immunosuppression alone resulted in no survival of transplanted hNSCs, while a combination of FK506 and anti-CD4 was required to achieve significant human cell survival ( $45 \%$ of initial dose) at 10 weeks posttransplantation [210]. Despite the lower level of overall engraftment in comparison with immunodeficient animals in this study, animals receiving combinatorial immunosuppression exhibited sufficient cell survival to enable demonstration of functional locomotor recovery following spinal cord injury. However, assessment of safety in the context of a cell population with proliferative potential is suboptimal under these conditions, as we have discussed previously [37], and should be carefully evaluated. Conversely, when immunodeficient animal models are used in traumatic CNS studies, human cell survival is dramatically increased (averaging 263\%), enabling a more robust evaluation of safety and efficacy [37].

\section{Sufficient duration to allow for evaluation of functional outcome}

As noted above, the second criteria for evaluating therapeutic success is sufficient time for transplanted cells to proliferate, migrate and either integrate with the host TBI brain or 


\section{Table 1. List of functional outcome tasks used in the traumatic brain injury field.}

\begin{tabular}{|c|c|c|c|c|c|c|c|}
\hline \multirow[t]{2}{*}{ Functional assessment } & \multirow{2}{*}{$\begin{array}{l}\text { Total } \\
\text { papers } \\
\text { assessing } \\
\text { task }(n)\end{array}$} & \multicolumn{3}{|c|}{$\geq 1$ month } & \multicolumn{3}{|c|}{$\geq 2$ months } \\
\hline & & $\begin{array}{l}\text { Papers } \\
\text { assessing } \\
\text { task at } \\
\geq 1 \text { month } \\
\text { (n) }\end{array}$ & $\begin{array}{l}\text { Papers with } \\
\text { deficits in } \\
\text { task at } \\
\geq 1 \text { month } \\
\text { (n) }\end{array}$ & $\begin{array}{l}\text { Papers with } \\
\text { deficits in } \\
\text { task at } \\
\geq 1 \text { month } \\
(\%)\end{array}$ & $\begin{array}{l}\text { Papers } \\
\text { assessing } \\
\text { task at } \\
\geq 2 \text { months } \\
\text { (n) }\end{array}$ & $\begin{array}{l}\text { Papers } \\
\text { with } \\
\text { deficits in } \\
\text { task at } \\
\geq 2 \text { months } \\
\text { (n) }\end{array}$ & $\begin{array}{l}\text { Papers with } \\
\text { deficits in } \\
\text { task at } \\
\geq 2 \text { months } \\
(\%)\end{array}$ \\
\hline Water maze - learning latency ${ }^{\dagger}$ & 261 & 72 & 55 & 76 & 28 & 18 & 64 \\
\hline Water maze - probe $^{\dagger}$ & 95 & 34 & 21 & 62 & 16 & 9 & 56 \\
\hline Global neurological assessment ${ }^{\dagger}$ & 45 & 20 & 15 & 75 & 7 & 3 & 43 \\
\hline Water maze - reversal ${ }^{\dagger}$ & 8 & 6 & 3 & 50 & 3 & 3 & 100 \\
\hline Forced swim test ${ }^{\dagger}$ & 6 & 5 & 3 & 60 & 3 & 3 & 100 \\
\hline Water maze - swim speed ${ }^{\dagger}$ & 96 & 29 & 3 & 10 & 13 & 2 & 15 \\
\hline Elevated plus maze $^{\dagger}$ & 11 & 7 & 4 & 57 & 2 & 2 & 100 \\
\hline Beam walking & 73 & 17 & 12 & 71 & 2 & 1 & 50 \\
\hline Rotarod & 31 & 12 & 6 & 50 & 2 & 1 & 50 \\
\hline Passive avoidance & 6 & 4 & 4 & 100 & 2 & 1 & 50 \\
\hline Y-maze & 7 & 5 & 3 & 60 & 2 & 1 & 50 \\
\hline Rotating pole & 6 & 4 & 3 & 75 & 2 & 1 & 50 \\
\hline Water maze - distance & 31 & 3 & 2 & 67 & 2 & 1 & 50 \\
\hline Water maze - visible platform & 12 & 3 & 3 & 100 & 1 & 1 & 100 \\
\hline Balance beam & 64 & 2 & 2 & 100 & 1 & 1 & 100 \\
\hline Open-field & 19 & 5 & 2 & 40 & 1 & 0 & 0 \\
\hline Water T-maze & 2 & 1 & 1 & 100 & 1 & 0 & 0 \\
\hline Social interaction & 2 & 2 & 0 & 0 & 1 & 0 & 0 \\
\hline Foot fault & 20 & 9 & 8 & 89 & 0 & 0 & 0 \\
\hline $\begin{array}{l}\text { Water maze - percent in correct } \\
\text { quadrant }\end{array}$ & 7 & 6 & 6 & 100 & 0 & 0 & 0 \\
\hline Bilateral tactile adhesive removal test & 8 & 5 & 2 & 40 & 0 & 0 & 0 \\
\hline Radial arm maze & 5 & 3 & 2 & 67 & 0 & 0 & 0 \\
\hline Barnes maze & 9 & 2 & 2 & 100 & 0 & 0 & 0 \\
\hline Vibrissae-elicited forelimb placing test & 4 & 2 & 2 & 100 & 0 & 0 & 0 \\
\hline Cylinder & 3 & 2 & 2 & 100 & 0 & 0 & 0 \\
\hline Inclined plane test & 8 & 2 & 1 & 50 & 0 & 0 & 0 \\
\hline Novel object recognition & 4 & 2 & 1 & 50 & 0 & 0 & 0 \\
\hline Water maze - memory score & 30 & 1 & 1 & 100 & 0 & 0 & 0 \\
\hline Water maze - working memory & 8 & 1 & 1 & 100 & 0 & 0 & 0 \\
\hline Dry maze test & 1 & 1 & 1 & 100 & 0 & 0 & 0 \\
\hline Forelimb flexion & 7 & 3 & 0 & 0 & 0 & 0 & 0 \\
\hline Fear conditioning - contextual & 7 & 2 & 0 & 0 & 0 & 0 & 0 \\
\hline Fear conditioning - cued & 3 & 2 & 0 & 0 & 0 & 0 & 0 \\
\hline Forepaw contraflexion & 1 & 1 & 0 & 0 & 0 & 0 & 0 \\
\hline
\end{tabular}




\section{Table 1. List of functional outcome tasks used in the traumatic brain injury field (cont.).}

\begin{tabular}{|c|c|c|c|c|c|c|c|}
\hline \multirow[t]{2}{*}{ Functional assessment } & \multirow{2}{*}{$\begin{array}{l}\text { Total } \\
\text { papers } \\
\text { assessing } \\
\text { task }(\mathrm{n})\end{array}$} & \multicolumn{3}{|c|}{$\geq 1$ month } & \multicolumn{3}{|c|}{$\geq 2$ months } \\
\hline & & $\begin{array}{l}\text { Papers } \\
\text { assessing } \\
\text { task at } \\
\geq 1 \text { month } \\
\text { (n) }\end{array}$ & $\begin{array}{l}\text { Papers with } \\
\text { deficits in } \\
\text { task at } \\
\geq 1 \text { month } \\
\text { (n) }\end{array}$ & $\begin{array}{l}\text { Papers with } \\
\text { deficits in } \\
\text { task at } \\
\geq 1 \text { month } \\
(\%)\end{array}$ & $\begin{array}{l}\text { Papers } \\
\text { assessing } \\
\text { task at } \\
\geq 2 \text { months } \\
\text { (n) }\end{array}$ & $\begin{array}{l}\text { Papers } \\
\text { with } \\
\text { deficits in } \\
\text { task at } \\
\geq 2 \text { months } \\
\text { (n) }\end{array}$ & $\begin{array}{l}\text { Papers with } \\
\text { deficits in } \\
\text { task at } \\
\geq 2 \text { months } \\
(\%)\end{array}$ \\
\hline $\begin{array}{l}\text { Reflexive forelimb and hindlimb } \\
\text { placing }\end{array}$ & 1 & 1 & 0 & 0 & 0 & 0 & 0 \\
\hline Staircase test & 1 & 1 & 0 & 0 & 0 & 0 & 0 \\
\hline
\end{tabular}

produce trophic support. Thus, study length of human stem cell transplantation experiments in TBI models must also be considered. Functional integration of transplanted stem cells as neurons has been demonstrated via electrophysiological measurement of neuronal firing between transplanted and host cells (although not in a TBI model) [211]. Integration of hNSC or oligodendrocyte precursors via electron microscopic evidence of remyelination of host axons by transplanted cells in spinal cord models [35,212] have also been shown. In contrast to functional integration with the host, promotion of recovery due to neurotrophic support of spared host tissue is also a possibility. Transplanted stem cells have been shown to secrete both prosurvival and immune-modulatory factors in vivo [213-215], which could lead to an increase in the amount of spared tissue or an increase in the health of the spared tissue, thus enabling greater neural network efficiency.

Depending on the type of human stem cell transplanted and the transplant location, the time frame for integration and terminal differentiation may range from several months in the case of human fetal-derived NSC-transplanted spinal cord [36] to 6 months in the case of human embryonic-derived NSC-transplanted brain studies [216]. Accordingly, in order to adequately assess the potential of a given donor cell population to yield repair, long-term studies (2 months or more) are required. Despite the desirability of long-term studies, very few (16\%) of the human stem cell transplantation studies in rodent TBI models reviewed here (five of 31 papers indicated in TaвLE 3) have exceeded 6 weeks duration post-transplant.

Of the 31 publications using a human stem cell population in a rodent model of TBI, 26 studied at 6 weeks or less post-transplant. Of these, nine did not perform functional assessments. Of the 17 studies that did perform some functional assessment, two reported no difference between controls and transplanted animals while 15 reported improvements on MWM $(\mathrm{n}=10)$, mNSS $(\mathrm{n}=8)$, rotarod $(\mathrm{n}=4)$, beam walk $(n=1)$ and/or limb function $(n=1)$; (the total does not equal 15 as some groups used more than one task). Only two of the 15 with positive functional outcomes also reported on human cell survival; Mahmood et al. [217], with $0.5 \%$ surviving human mesenchymal stem cells (hMSCs) at 4 weeks post-transplant; and Hong et al. [218] with $6.8 \%$ surviving human umbilical cord stem cells at 3 weeks post-transplant. Accordingly, the lack of surviving human cells and the short duration of the majority of TBI experiments make interpretation of mechanism and capacity to exert sustained functional effects difficult. In particular, the short time course of survival and functional assessment suggest that while the positive effects seen could be due to immune-modulation and/or trophic mechanisms, cellular integration is unlikely as a mechanism (as discussed above).

Of the five studies that conducted evaluations for 6 weeks or greater, the results have been mixed in terms of human cell survival and/or functional recovery. Two studies reported partial data on long-term cell survival, but did not examine functional outcomes after such long-term engraftment. Wennersten et al. noted human cell survival at both 6 weeks and 6 months post-transplant of human fetal NSCs, but reported only $0.2 \%$ human cell survival at 6 weeks (determined by counting human nuclei in four sequential sections) in cyclosporin A-treated Sprague-Dawley rats [219]. Quantification of human cells at 6 months was not performed. Approximately $5 \%$ of human 


\section{Table 2. Models and functional outcome tasks with long-term deficits at 2, 3, 6 and 12 months postinjury.}

\begin{tabular}{|c|c|c|c|c|}
\hline Task & 2 months & 3 months & 6 months & 12 months \\
\hline \multicolumn{5}{|l|}{ Fluid percussion injury } \\
\hline Beam walking & Shultz (2013) [131] & - & - & - \\
\hline Elevated plus maze & $\begin{array}{l}\text { Shultz (2012) [189] } \\
\text { Shultz (2013) [131] }\end{array}$ & - & - & - \\
\hline Forced swim test & Shultz (2012) [189] & - & - & - \\
\hline Global neurological assessment & - & Schütz (2006) [112] & Hayward (2010) [100] & - \\
\hline Water maze - distance & Bramlett (1997) [251] & & & \\
\hline Water maze - learning latency & $\begin{array}{l}\text { Phillips (1997) [159] } \\
\text { Sanders (1999) [160] } \\
\text { Schütz (2006) [112] } \\
\text { Shultz (2012) [189] } \\
\text { Shultz (2013) [131] }\end{array}$ & Browne (2006) [165] & $\begin{array}{l}\text { Browne (2004) [162] } \\
\text { Hayward (2010) [100] }\end{array}$ & Pierce (1998) [107] \\
\hline Water maze - probe & Thompson (2006) [164] & - & $\begin{array}{l}\text { Immonen (2009) [194] } \\
\text { Hayward (2010) [100] }\end{array}$ & - \\
\hline Water maze - reversal & $\begin{array}{l}\text { Thompson (2006) [164] } \\
\text { Shultz (2012) [189] } \\
\text { Shultz (2013) [131] }\end{array}$ & - & - & - \\
\hline Water maze - swim speed & Shultz (2012) [189] & - & Hayward (2010) [100] & \\
\hline \multicolumn{5}{|c|}{ Weight drop impact-acceleration/closed head injury } \\
\hline Forced swim test & - & $\begin{array}{l}\text { Milman (2005) [200] } \\
\text { Milman (2008) [201] }\end{array}$ & - & - \\
\hline Passive avoidance & Milman (2008) [201] & - & - & - \\
\hline Rotarod & Laurer (2001) [148] & - & - & - \\
\hline Rotating pole test & Laurer (2001) [148] & - & - & - \\
\hline Water maze - learning latency & - & $\begin{array}{l}\text { Adelson }(2000)[182] \\
\text { Uryu }(2002)[192] \\
\text { Zohar (2003) [184] } \\
\text { Zohar (2006) [185] }\end{array}$ & - & Meehan (2012) [191] \\
\hline Water maze - probe & - & $\begin{array}{l}\text { Adelson (2000) [182] } \\
\text { Zohar (2003) [184] }\end{array}$ & - & - \\
\hline Water maze - visible platform & - & Adelson (2000) [182] & - & - \\
\hline \multicolumn{5}{|l|}{ Controlled cortical impact } \\
\hline Balance beam & - & - & Cheng (2012) [121] & - \\
\hline Global neurological assessment & - & - & - & Shelton (2008) [115] \\
\hline Water maze - learning latency & $\operatorname{Han}(2009)$ [181] & Byrnes (2012) [177] & Cheng (2012) [121] & Dixon (1999) [171] \\
\hline Water maze - probe & $\begin{array}{l}\text { Han }(2009)[181] \\
\text { Chauhan (2010) [175] } \\
\text { Chauhan (2011) [176] }\end{array}$ & - & - & Dixon (1999) [171] \\
\hline Y-maze & Chauhan (2010) [175] & - & - & - \\
\hline
\end{tabular}

cells colocalized with neuronal or astrocytic markers; no oligodendrocytes were detected. The authors noted that the hippocampus appeared more conducive to neuronal differentiation than the cortex. No functional tasks were evaluated at any time point in Wennersten's study [219]. Nichols et al. transplanted retinoic acid-primed CD133+ABCG2+CXCR4 ${ }^{+}$hMSCs into the lateral ventricle of male Sprague-Dawley rats $24 \mathrm{~h}$ after FPI; no immunosuppression was used [209]. The transplanted cells were reported to integrate within the host and differentiate into cells expressing both immature and mature neural lineage markers. However, the cells were 
Table 3. Human cellular therapy studies in rodent models of traumatic brain injury.

\begin{tabular}{|c|c|c|c|c|c|c|}
\hline Study (year) & $\begin{array}{l}\text { Injury } \\
\text { model }\end{array}$ & Human cell population & $\begin{array}{l}\text { Terminal time } \\
\text { point postinjection }\end{array}$ & $\begin{array}{l}\text { Quantified cell } \\
\text { survival (\%) }\end{array}$ & Functional assessment & Ref. \\
\hline $\begin{array}{l}\text { Nichols et al. } \\
(2013)^{\dagger}\end{array}$ & FPI & hMSCs & 12 weeks & 21 & $\begin{array}{l}\text { Improved MWM (at 11-15 dpi } \\
\text { only) }\end{array}$ & [209] \\
\hline $\begin{array}{l}\text { Hong et al. } \\
\text { (2011) }\end{array}$ & WDIA & hUCSCs & 3 weeks & 6.8 & Improved MWM & [218] \\
\hline $\begin{array}{l}\text { Mahmood et al. } \\
(2003)\end{array}$ & $\mathrm{CCl}$ & hMSCs & 4 weeks & $0.5-0.6$ & Improved rotarod and mNSS & {$[217]$} \\
\hline $\begin{array}{l}\text { Wennersten } \\
\text { et al. }(2006)^{\dagger}\end{array}$ & WDIA & Fetal hNSCs & $\begin{array}{l}3 \text { or } 6 \text { weeks, or } \\
6 \text { months }\end{array}$ & $0.03-0.2$ & NA & [219] \\
\hline $\begin{array}{l}\text { Hagen et al. } \\
(2003)\end{array}$ & $\mathrm{CCl}$ & Fetal hNSCs & 6 days & $0.12-0.95$ & NA & [230] \\
\hline $\begin{array}{l}\text { Mahmood et al. } \\
(2005)^{\dagger}\end{array}$ & $\mathrm{CCl}$ & hMSCs & 12 weeks & Not reported & Improved mNSS & [222] \\
\hline $\begin{array}{l}\text { Zhang et al. } \\
(2005)^{\dagger}\end{array}$ & FPI & NT2N neurons & 4,8 and 12 weeks & Not reported & No differences & [220] \\
\hline Lu et al. (2002) & $\mathrm{CCl}$ & hUCSCs & 1 month & Not reported & Improved rotarod and mNSS & [231] \\
\hline $\begin{array}{l}\text { Watson et al. } \\
(2003)\end{array}$ & $\mathrm{CCl}$ & NT2N neurons & 4 weeks & Not reported & Improved MWM & [232] \\
\hline $\begin{array}{l}\text { Longhi et al. } \\
\text { (2004) }\end{array}$ & $\mathrm{CCl}$ & NT2N neurons & 4 weeks & Not reported & Improved MWM & {$[114]$} \\
\hline Lu et al. (2007) & $\mathrm{CCl}$ & hMSCs & 5 weeks & Not reported & Improved MWM and mNSS & [79] \\
\hline Qu et al. (2009) & $\mathrm{CCl}$ & hMSCs & 5 weeks & Not reported & Improved MWM & [233] \\
\hline $\begin{array}{l}\text { Kim et al. } \\
(2010)\end{array}$ & $\mathrm{CCl}$ & hMSCs & $\begin{array}{l}1,2,8,15,22 \text { and } \\
29 \text { days }\end{array}$ & Not reported & Improved rotarod and mNSS & [234] \\
\hline Li et al. (2011) & $\mathrm{CCl}$ & hMSCs & 6 weeks & Not reported & Improved MWM and mNSS & [238] \\
\hline $\begin{array}{l}\text { Jiang et al. } \\
\text { (2011) }\end{array}$ & $\mathrm{CCl}$ & hMSCs & 6 weeks & Not reported & Improved MWM and mNSS & [239] \\
\hline $\begin{array}{l}\text { Zanier et al. } \\
\text { (2011) }\end{array}$ & $\mathrm{CCl}$ & hUCSCs & 5 weeks & Not reported & $\begin{array}{l}\text { Improved MWM, mNSS and } \\
\text { beam walk }\end{array}$ & [240] \\
\hline $\begin{array}{l}\text { Poltavtseva } \\
\text { et al. (2012) }\end{array}$ & $\mathrm{CCl}$ & Fetal hMSCs and hNSCs & 3 weeks & Not reported & Improved limb function & [241] \\
\hline $\begin{array}{l}\text { Hung et al. } \\
\text { (2010) }\end{array}$ & FPI & Immortalized hMSCs & 2, 7 and 14 days & Not reported & NA & [242] \\
\hline $\begin{array}{l}\text { Muir et al. } \\
\text { (1999) }\end{array}$ & FPI & NT2N neurons & 2 weeks & Not reported & No differences & [243] \\
\hline $\begin{array}{l}\text { Philips et al. } \\
\text { (2001) }\end{array}$ & FPI & NT2N neurons & 2 and 4 weeks & Not reported & No differences & [149] \\
\hline \multicolumn{7}{|c|}{$\begin{array}{l}\text { A total of } 31 \text { papers have transplanted human stem cells into a rodent model of traumatic brain injury. Only six of these papers reported a quantified cell survival, and } \\
\text { none of them used immunodeficient rodent strains. Injury model, transplanted human stem cell population, length of study, quantified cell survival and functional } \\
\text { assessments in treated compared with untreated animals is shown. } \\
\text { 'Studies that assessed animals at a terminal time point greater than } 6 \text { weeks post-transplant. } \\
\text { CCl: Controlled cortical impact; dpi: Days postinjury; FPI: Fluid percussion injury; hMSC: Human mesenchymal stem cell; hNSC: Human neural stem cell; } \\
\text { hUCSC: Human umbilical cord stem cell; mNSS: Modified neurological severity score; MWM: Morris water maze; NA: Not assessed; PBBI: Penetrating ballistic-like } \\
\text { brain injury; WDIA: Weight drop impact-acceleration. }\end{array}$} \\
\hline
\end{tabular}




\section{Table 3. Human cellular therapy studies in rodent models of traumatic brain injury (cont.).}

\begin{tabular}{|c|c|c|c|c|c|c|}
\hline Study (year) & $\begin{array}{l}\text { Injury } \\
\text { model }\end{array}$ & Human cell population & $\begin{array}{l}\text { Terminal time } \\
\text { point postinjection }\end{array}$ & $\begin{array}{l}\text { Quantified cell } \\
\text { survival (\%) }\end{array}$ & Functional assessment & Ref. \\
\hline $\begin{array}{l}\text { Gao et al. } \\
(2006)\end{array}$ & FPI & Fetal hNSCs & 2 weeks & Not reported & Improved MWM & [244] \\
\hline $\begin{array}{l}\text { Wang et al. } \\
(2012)\end{array}$ & FPI & Fetal hNSCs & 4 days & Not reported & NA & [245] \\
\hline $\begin{array}{l}\text { Chen et al. } \\
(2009)\end{array}$ & PBBI & Human amniotic cells & $1,2,3$ and 4 weeks & Not reported & NA & [246] \\
\hline $\begin{array}{l}\text { Chen et al. } \\
\text { (2011) }\end{array}$ & PBBI & Human amniotic cells & 2 weeks & Not reported & Improved rotarod & {$[247]$} \\
\hline $\begin{array}{l}\text { Wennersten } \\
\text { et al. (2004) }\end{array}$ & WDIA & Fetal hNSCs & 2 and 6 weeks & Not reported & NA & [248] \\
\hline $\begin{array}{l}\text { Al Nimer et al. } \\
\text { (2004) }\end{array}$ & WDIA & Fetal hNSCs & 6 weeks & Not reported & NA & [249] \\
\hline
\end{tabular}

prelabeled with a fluorescein dye (carboxyfluorescein succinimidyl ester) prior to transplantation and not detected with human-specific markers postmortem, making positive identification difficult and colocalization with neural lineage markers uncertain. Furthermore, the methods section of [209] indicated that 500,000 cells were transplanted, while Figure 9A of [209] shows 100,000 cells transplanted with approximately 21,000 surviving in TBI rats (21\%). Finally, function on the MWM was only examined 11-15 days post-transplant, not longterm, where significance relative to uninjured controls was observed for 'primed' hMSCs but not unprimed hMSCs [209].

Additionally, three studies reported on both engraftment/survival and long-term functional assessments. Zhang et al. transplanted human NT2N neurons into a FPI model of TBI in cyclosporin A-treated Sprague-Dawley rats and reported human cell survival at 12 weeks post-transplant and the presence of human synaptophysin-positive structures [220]. However, no human cell quantification was performed and there were no functional differences in cognitive or motor performance 12 weeks posttransplant between groups injected with either NT2Ns, human fibroblasts or vehicle. Tasks assessed included a composite neuroscore, beam balance rotating pole, and adhesive tape removal. Skardelly et al. transplanted human fetal-derived neural progenitor cells via local or systemic injection into Sprague-Dawley rats $24 \mathrm{~h}$ after a severe CCI $(2.5 \mathrm{~mm}$ depth, $4 \mathrm{~m} / \mathrm{s}$ impact) [221]. Cyclosporin A and prednisolone were used for immunosuppression. Functional motor improvements (by blinded observer) on both rotarod and mNSS were observed, but only for systemically administered cells. PKH-26 prelabeled human cells were detected 12 weeks post-transplant, but no human cell quantification was performed. Similarly, Mahmood et al. reported motor improvement (mNSS) at 12 weeks postadministration of human marrow stromal cells into Wistar rats [222]. A total of 2, 4 or 8 million cells were administered systemically via tail vein $24 \mathrm{~h}$ post-CCI-induced TBI $(2.5 \mathrm{~mm}$ depth, $4 \mathrm{~m} / \mathrm{s}$ impact). All three doses of hMSCs resulted in significant improvements in mNSS, which was assessed blind to treatment. Nonstereological human cell quantification was performed in three sections per animal and showed that human cells survived 12 weeks postinjection; none were NeuN- or GFAP-positive.

While two 12 week duration studies report functional improvements after human stem cell treatment, the absence of stereological quantification of surviving human cells makes it difficult to associate functional gains with human cells when the extent of human cell survival and integration after transplantation are unclear. Given the time, expense and use of animals, we must be rigorous when designing 


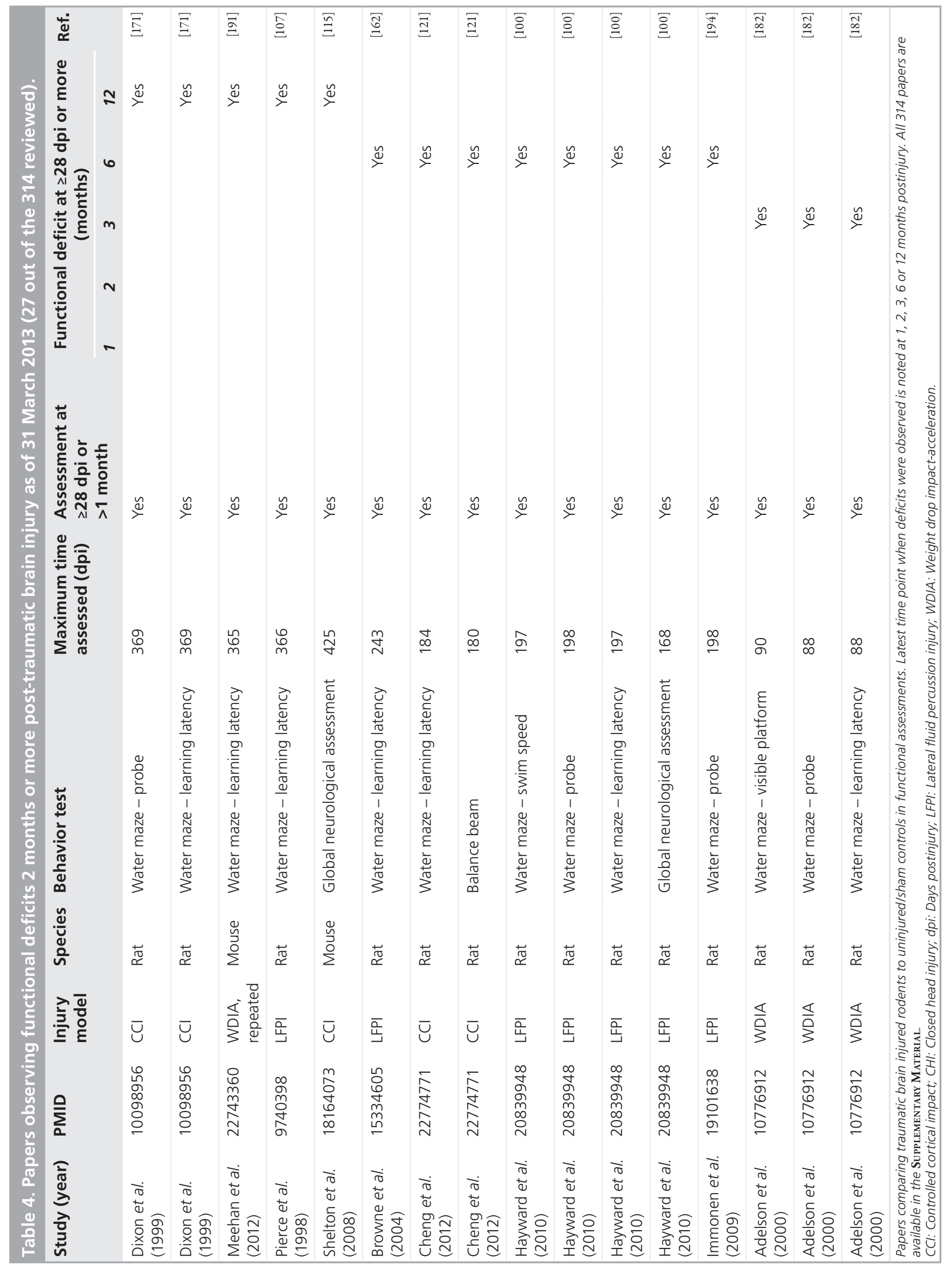




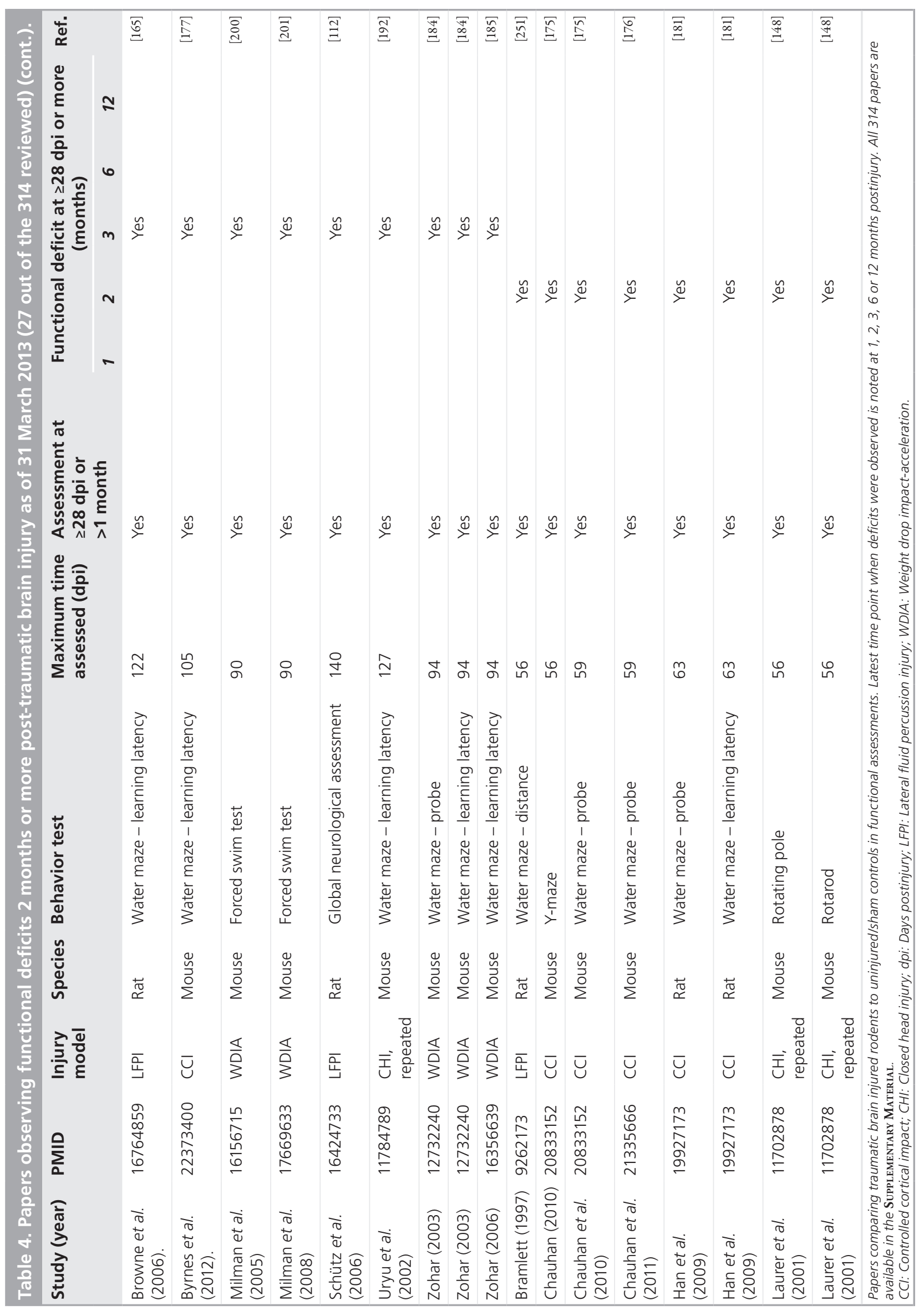




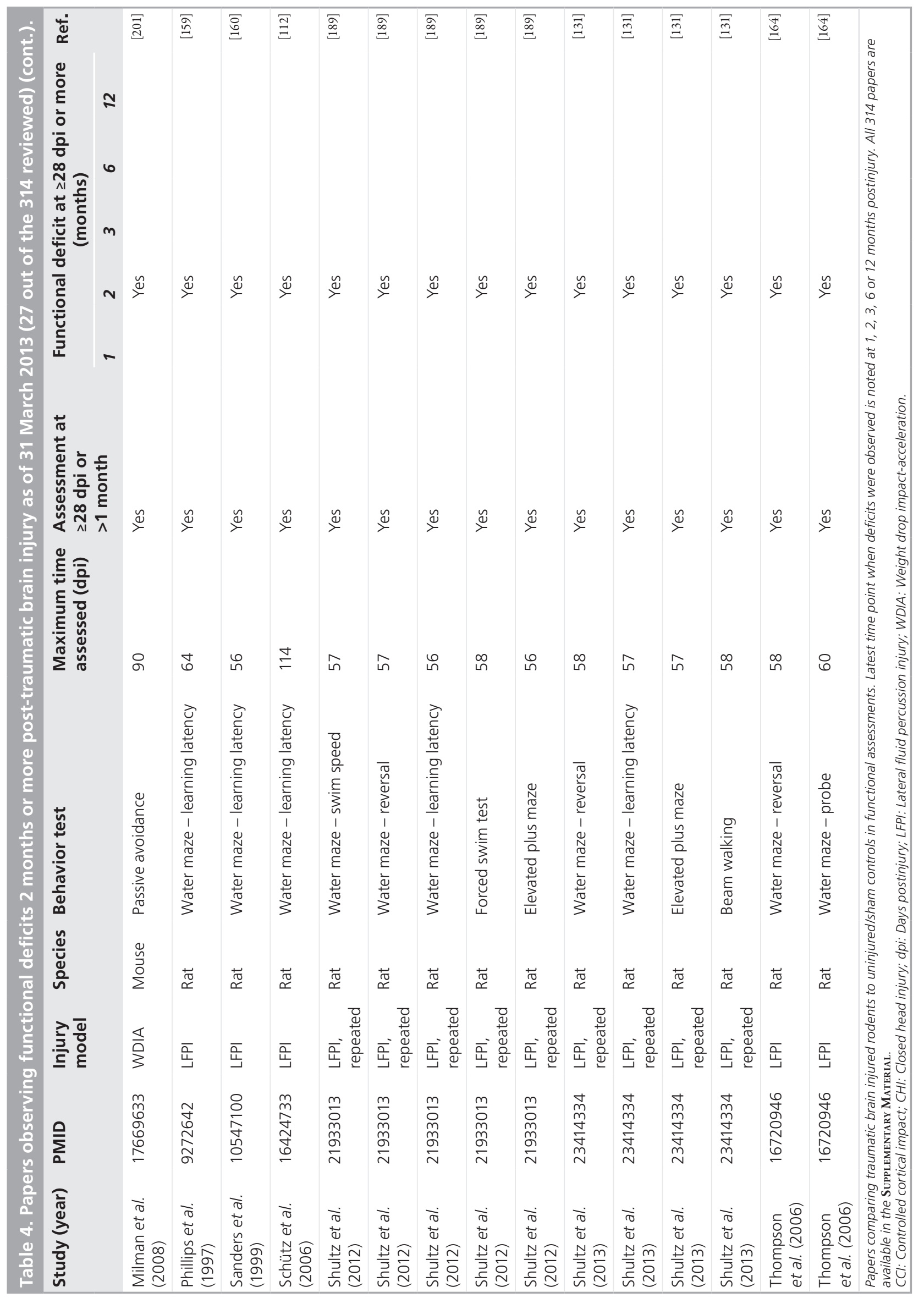


human stem cell transplantation studies to enable sufficient cell survival and allow adequate time for terminal cell differentiation, and we must also be rigorous in our quantification and analysis so that the potential for misinterpretation, whether beneficial or detrimental, is minimized. Taken together, these studies highlight the potential for both long-term survival of transplanted human cell populations as well as the ability for transplanted cells to possibly integrate within the host and lead to functional improvements post-TBI. However, these studies also suggest that to improve the interpretability of future CNS injury/human cell transplantation studies, researchers must accurately report engraftment (the number of transplanted animals with any surviving cells) and quantify cell survival (absolute number of cells per animal) so that comparisons of different treatments can be made, and use immunodeficient animal strains or combinatorial immunosuppression protocols whenever possible to maximize cell survival and ensure that safety/efficacy can be adequately evaluated. A complete list of all 314 papers analyzed in this review is in the Supplementary Material (see online at www.futuremedicine.com/doi/ suppl/10.2217/rme.13.41) and in abbreviated form in Taвце 4 , and is available as an expanded spreadsheet from the authors upon request.

\section{Conclusion}

Despite the fact that distinct preclinical models of focal and diffuse TBI exist, imaging data in the majority of clinical TBI cases shows evidence characteristic of a mixed etiology. Further, the pathophysiological features of focal TBI (prominent neuronal loss) and diffuse TBI (prominent axonal pathology) may both benefit from neuroprotective and/or cell replacement strategies. As a result, and as many researchers have suggested, it may be likely that combinatorial therapeutic approaches will ultimately be necessary for success in the clinical setting, and the selection of outcome measures in preclinical experiments must be sufficiently characterized and match clinical features of TBI that are planned for assessment in a clinical trial.

Because human stem cells take longer to mature and differentiate than rodent stem cells, we recommend a minimum of 2 months of in vivo incubation to allow for differentiation and integration of the human cells within the host. Of course, allowing the survival of hNSCs for greater than 2 months posttransplant would clearly be ideal, but there are many factors that limit such studies: financial resources; personnel; animal lifespan; and housing are all limited. Nonetheless, it seems clear that this minimal time frame will be necessary for adequate assessment of efficacy and mechanisms of action. As stated in 'Criteria for predictive models of TBI \& assessment of stem cell therapies' section, there are three primary mechanisms that could underlie the efficacy of a human stem cell transplant: immune modulation; trophic factors; and/or functional integration. If, in fact, differentiation and integration, and not trophic factor secretion, underlies the activity of a given population of transplanted cells, then 2 months would be the minimum time needed to demonstrate in vivo efficacy. This 2 month period is based on extensive preclinical data in rodent models of spinal cord injury (where there are more human stem cell studies to date than the TBI field). Studies that show rapid improvements post-transplant ( $\leq 4$ weeks) with human cells have been shown to correlate with trophic factor generation [223]; by contrast, studies with integration as an underlying mechanism have not shown evidence of improvement until 6-8 weeks post-transplantation [35,36,38]. Critically, while trophic effects might be observed at earlier time points, it will also be important to demonstrate the sustainability of such an effect, supporting the importance of an extended period of in vivo observation. Furthermore, regulatory bodies will likely require at least 6 months survival post-transplantation for assessment of toxicology/safety, particularly in the context of assessing cell abnormalities.

Related to these considerations and a particular issue in the context of cell-based therapeutic candidates, a variety of data in animal models have suggested that direct pharmacological modulation of the immune response after TBI can exert neuroprotective effects; for example, administration of clinical immunosuppressants such as cyclosporin A [224,225]. Conversely, it is increasingly clear that traumatic CNS injury, including both TBI and spinal cord injury, can result in peripheral immunodepression in both animal models and in the clinical setting [226-228], suggesting the potential for increased susceptibility to postinjury infectious complications and that the inflammatory environment post-TBI may be a double-edged sword [229]. It will be particularly important to consider immunosuppressive regimens and the timing of cell transplantation paradigms in this complex context. 
In summary, we recommend two principal criteria for testing the safety and efficacy of human donor cell populations in preclinical TBI models. First, a model in which sufficient engraftment of donor human cells can be achieved to reliably test safety and efficacy across a xenotransplantation barrier will be necessary; this requirement will likely require immunodeficient animal models, or dramatically improved methods of achieving adequate immunosuppression. Second, a model in which the potential functional impact, either in terms of improvement (efficacy) or determent (safety) can be reliably measured for an extended period of time post-transplantation ( $\geq 2$ months).

\section{Future perspective}

In the future, it is likely that better animal models of TBI will be developed, including models of repeated TBI, used of humanized immune system animals and/or the characterization of immunodeficient animals models to better allow for assessment of human donor cell populations. Preclinical testing will also expand to more long-term studies and studies that utilize multiple outcome measures that better overlap functional outcome assessment in the human population. We also predict that advancements in understanding and testing mechanisms of action will reveal that different cell populations exert effects via distinct but overlapping actions on the injured host. Finally, we expect that increased application of RIGOR and STAIR standards will strengthen the translatability of preclinical animal testing to support clinical trials in TBI.

\section{Acknowledgements}

The authors would like to thank A Sudarshan for assistance reviewing a portion of papers in TABLE 4 .

\section{Financial \& competing interests disclosure}

This work was supported by a CIRM ETA II grant (TR201767) to BJ Cummings, a DoD DMRDP grant (DM103001) to AJ Anderson, a CIRM Research Training Program II grant (TG2-01152) to DL Haus and a CIRM Stem Cell Research Biotechnology Training Program at CSULB grant to L Klig (TB1-01182), which supported $G A$ Lacuesta. The authors have no other relevant affiliations or financial involvement with any organization or entity with a financial interest in or financial conflict with the subject matter or materials discussed in the manuscript apart from those disclosed.

No writing assistance was utilized in the production of this manuscript.

\section{Open Access}

This work is licensed under the Creative Commons Attribution-NonCommercial 3.0 Unported License. To view a copy of this license, visit http://creativecommons. org/licenses/by-nc-nd/3.0/

\section{Executive summary}

\section{Most traumatic brain injury preclinical research is short term}

- Most research in the traumatic brain injury (TBI) field has focused on short-term outcomes. The majority (68\%) of papers reviewed did not evaluate functional outcomes past 1 month post-TBI (213 of 314 papers).

- A total of $90 \%$ of TBI papers reviewed did not make a functional assessment 2 or more months following injury (282 of 314$)$; whereas 32 papers have looked long term ( $\geq 2$ months).

- Most (84\%) TBI papers that looked long term (27 of 32) demonstrated functional deficits at 2 months postinjury, the minimum time during which one could reasonably expect cell integration to exert an effect as a recovery of function mechanism.

\section{Studies of longer duration are needed}

- Sustained and significant functional deficits of at least 2 months duration post-TBI are necessary before safety and efficacy can be demonstrated using any transplanted human stem cell population. Deficits can be cognitive, emotional and/or motor in origin.

- Two months post-transplantation is also the minimum amount of time needed to allow for proliferation, migration, differentiation and/or integration of human neural stem cells into the injured host.

\section{No immunodeficient animal models of TBI exist}

- No preclinical TBI models from the review period employed immunodeficient animal models nor characterized TBI in an immunodeficient preclinical model that would enable maximal theoretical cell engraftment for assessment of safety and efficacy.

- TBI cell-therapy studies do not routinely use combined immunosuppression.

\section{Human cell quantification is rare \& efficacy even rarer}

- Only $16 \%$ of TBI transplantation papers from the review period, where human cell transplants were administered (five of 31 papers), quantified human cell engraftment/survival. A total of $84 \%$ did not report on cell survival.

- Human cell survival, when reported, was low, ranging from $0.03 \%$ of the initial dose to a maximum of $21 \%$ (average: $4.7 \%$ ).

- Only $9.6 \%$ of TBI transplantation papers using a human cell population reported functional efficacy at > 2 months post-transplantation (three of 31 papers). 


\section{References}

Papers of special note have been highlighted as: " of interest

1 Menon DK, Schwab K, Wright DW, Maas AI. Position statement: definition of traumatic brain injury. Arch. Phys. Med. Rehabil. 91(11), 1637-1640 (2010).

2 Management of Concussion/mTBI Working Group. VA/DoD clinical practice guideline for management of concussion/mild traumatic brain injury. J. Rehabil. Res. Dev. 46(6), CP1-CP68 (2009).

3 Moretti L, Cristofori I, Weaver SM, Chau A, Portelli JN, Grafman J. Cognitive decline in older adults with a history of traumatic brain injury. Lancet Neurol. 11(12), 1103-1112 (2012).

4 Hall RC, Hall RC, Chapman MJ. Definition, diagnosis, and forensic implications of postconcussional syndrome. Psychosomatics 46(3), 195-202 (2005).

5 Martland HS. Punch drunk. J. Am. Med. Assoc. 91, 1103-1107 (1928).

6 Parker HL. Traumatic encephalopathy ('punch drunk') of professional pugilists. J. Neurol. Psychopathol. 15(57), 20-28 (1934).

7 Millspaugh J. Dementia pugilistica (punch drunk). US Navy Med. Bull. 35, 297-303 (1937).

8 Critchley M. Medical aspects of boxing, particularly from a neurological standpoint. Br. Med. J. 1(5015), 357-362 (1957).

9 Omalu BI, Dekosky ST, Minster RL, Kamboh MI, Hamilton RL, Wecht CH. Chronic traumatic encephalopathy in a National Football League player. Neurosurgery 57(1), 128-134; discussion 128-134 (2005).

10 Mckee AC, Cantu RC, Nowinski CJ et al. Chronic traumatic encephalopathy in athletes: progressive tauopathy after repetitive head injury. J. Neuropathol. Exp. Neurol. 68(7), 709-735 (2009).

11 Langlois JA, Marr A, Mitchko J, Johnson RL. Tracking the silent epidemic and educating the public: CDC's traumatic brain injuryassociated activities under the TBI Act of 1996 and the Children's Health Act of 2000. J. Head Trauma. Rehabil. 20(3), 196-204 (2005).

12 Scudellari M. Brain, interrupted. Scientist 24(7), 36-41 (2010).

13 Faul M, Xu L, Wald MM, Coronado VG. Traumatic Brain Injury in the United States: Emergency Department Visits, Hospitalizations, and Deaths. CDC, GA, USA (2010).

14 Coronado VG, Xu L, Basavaraju SV et al. Surveillance for traumatic brain injury-related deaths - United States, 1997-2007. MMWR Surveill. Summ. 60(5), 1-32 (2011).
15 Narayan RK, Michel ME, Ansell B et al. Clinical trials in head injury. J. Neurotrauma 19(5), 503-557 (2002).

16 Corrigan JD, Selassie AW, Orman JA. The epidemiology of traumatic brain injury. J. Head Trauma. Rehabil. 25(2), 72-80 (2010).

17 Roozenbeek B, Maas AI, Menon DK. Changing patterns in the epidemiology of traumatic brain injury. Nat. Rev. Neurol. 9(4), 231-236 (2013).

18 Thurman DJ, Alverson C, Dunn KA, Guerrero J, Sniezek JE. Traumatic brain injury in the United States: a public health perspective. J. Head Trauma. Rehabil. 14(6), 602-615 (1999).

19 Coronado VG, McGuire LC, Faul MD, Sugerman DE, Peaerson WS. Traumatic brain injury epidemiology and public health issues. In: Perspectives on Clinical Care, Public Health and Research (2nd Edition). Zasler ND, Katz DI, Zafonte RD (Eds). Demos Medical Publishing LLC, NY, USA (2012).

20 Finkelstein E, Corso P, Miller T, Assiciates A. The Incidence and Economic Burden of Injuries in the United States. Oxford University Press, NY, USA (2006).

21 Shigaki CL, Johnstone B, Schopp LH. Financial and vocational outcomes 2 years after traumatic brain injury. Disabil. Rehabil. 31(6), 484-489 (2009).

22 McIntosh TK, Smith DH, Meaney DF, Kotapka MJ, Gennarelli TA, Graham DI. Neuropathological sequelae of traumatic brain injury: relationship to neurochemical and biomechanical mechanisms. Lab. Invest. 74(2), 315-342 (1996).

23 Maas AI, Marmarou A, Murray GD, Teasdale SG, Steyerberg EW. Prognosis and clinical trial design in traumatic brain injury: the IMPACT study. J. Neurotrauma 24(2), 232-238 (2007).

24 Andriessen TM, Jacobs B, Vos PE. Clinical characteristics and pathophysiological mechanisms of focal and diffuse traumatic brain injury. J. Cell. Mol. Med. 14(10), 2381-2392 (2010).

25 Morganti-Kossmann MC, Yan E, Bye N. Animal models of traumatic brain injury: is there an optimal model to reproduce human brain injury in the laboratory? Injury 41(Suppl. 1), S10-S13 (2010).

26 Graham DI, Adams JH, Nicoll JA, Maxwell WL, Gennarelli TA. The nature, distribution and causes of traumatic brain injury. Brain Pathol. 5(4), 397-406 (1995).

27 Buki A, Povlishock JT. All roads lead to disconnection? - Traumatic axonal injury revisited. Acta Neurochir. (Wien.) 148(2), 181-193; discussion 193-194 (2006).
28 Newcombe V, Chatfield D, Outtrim J et al. Mapping traumatic axonal injury using diffusion tensor imaging: correlations with functional outcome. PLoS ONE 6(5), e19214 (2011).

29 Sidaros A, Skimminge A, Liptrot MG et al. Long-term global and regional brain volume changes following severe traumatic brain injury: a longitudinal study with clinical correlates. Neuroimage 44(1), 1-8 (2009).

30 Skandsen T, Kvistad KA, Solheim O, Strand IH, Folvik M, Vik A. Prevalence and impact of diffuse axonal injury in patients with moderate and severe head injury: a cohort study of early magnetic resonance imaging findings and 1-year outcome. J. Neurosurg. 113(3), 556-563 (2010).

31 Maas AI, Menon DK. Traumatic brain injury: rethinking ideas and approaches. Lancet Neurol. 11(1), 12-13 (2012).

32 Fisher M, Feuerstein G, Howells DW et al. Update of the stroke therapy academic industry roundtable preclinical recommendations. Stroke 40(6), 2244-2250 (2009).

33 Recommendations for standards regarding preclinical neuroprotective and restorative drug development. Stroke 30(12), 2752-2758 (1999).

- STAIR guidelines for developing preclinical models that apply to traumatic brain injury as well as stroke.

34 De Feo D, Merlini A, Laterza C, Martino G. Neural stem cell transplantation in central nervous system disorders: from cell replacement to neuroprotection. Curr. Opin. Neurol. 25(3), 322-333 (2012).

35 Cummings BJ, Uchida N, Tamaki SJ et al. Human neural stem cells differentiate and promote locomotor recovery in spinal cordinjured mice. Proc. Natl Acad. Sci. USA 102(39), 14069-14074 (2005).

36 Hooshmand MJ, Sontag CJ, Uchida N, Tamaki S, Anderson AJ, Cummings BJ. Analysis of host-mediated repair mechanisms after human CNS-stem cell transplantation for spinal cord injury: correlation of engraftment with recovery. PLoS ONE 4(6), e5871 (2009).

37 Anderson AJ, Haus DL, Hooshmand MJ, Perez H, Sontag CJ, Cummings BJ. Achieving stable human stem cell engraftment and survival in the CNS: is the future of regenerative medicine immunodeficient? Regen. Med.6(3), 367-406 (2011).

- Review of xenotransplantation in the context of CNS disorders.

38 Salazar DL, Uchida N, Hamers FP, Cummings BJ, Anderson AJ. Human neural stem cells differentiate and promote locomotor recovery in an early chronic spinal cord injury 
NOD-scid mouse model. PLoS ONE 5(8), e12272 (2010).

39 Piltti KM, Salazar DL, Uchida N, Cummings BJ, Anderson AJ. Safety of epicenter versus intact parenchyma as a transplantation site for human neural stem cells for spinal cord injury therapy. Stem Cells Transl. Med. 2(3), 204-216 (2013).

40 Xiong Y, Mahmood A, Chopp M. Animal models of traumatic brain injury. Nat. Rev. Neurosci. 14(2), 128-142 (2013).

- Informative and up-to-date review on preclinical traumatic brain injury models.

41 Lindgren S, Rinder L. Experimental studies in head injury. I. Some factors influencing results of model experiments. Biophysik 2(5), 320-329 (1965).

42 Sullivan HG, Martinez J, Becker DP, Miller JD, Griffith R, Wist AO. Fluid-percussion model of mechanical brain injury in the cat. J. Neurosurg. 45(5), 521-534 (1976).

43 Dixon CE, Lyeth BG, Povlishock JT et al. A fluid percussion model of experimental brain injury in the rat. J. Neurosurg. 67(1), 110-119 (1987).

44 Zink BJ, Walsh RF, Feustel PJ. Effects of ethanol in traumatic brain injury. J. Neurotrauma 10(3), 275-286 (1993).

45 Stern SA, Zink BJ, Mertz M, Wang X, Dronen SC. Effect of initially limited resuscitation in a combined model of fluidpercussion brain injury and severe uncontrolled hemorrhagic shock. J. Neurosurg. 93(2), 305-314 (2000).

46 Carbonell WS, Maris DO, McCall T, Grady MS. Adaptation of the fluid percussion injury model to the mouse. J. Neurotrauma 15(3), 217-229 (1998).

47 McIntosh TK, Vink R, Noble L et al. Traumatic brain injury in the rat: characterization of a lateral fluid-percussion model. Neuroscience 28(1), 233-244 (1989).

48 Lowenstein DH, Thomas MJ, Smith DH, McIntosh TK. Selective vulnerability of dentate hilar neurons following traumatic brain injury: a potential mechanistic link between head trauma and disorders of the hippocampus. J. Neurosci. 12(12), 4846-4853 (1992).

49 Hicks R, Soares H, Smith D, McIntosh T. Temporal and spatial characterization of neuronal injury following lateral fluidpercussion brain injury in the rat. Acta Neuropathol. 91(3), 236-246 (1996).

50 Vink R, Mullins PG, Temple MD, Bao W, Faden AI. Small shifts in craniotomy position in the lateral fluid percussion injury model are associated with differential lesion development. J. Neurotrauma 18(8), 839-847 (2001).
51 Floyd CL, Golden KM, Black RT, Hamm RJ, Lyeth BG. Craniectomy position affects Morris water maze performance and hippocampal cell loss after parasagittal fluid percussion. J. Neurotrauma 19(3), 303-316 (2002).

52 Faden AI, Demediuk P, Panter SS, Vink R. The role of excitatory amino acids and NMDA receptors in traumatic brain injury. Science 244(4906), 798-800 (1989).

53 Cortez SC, McIntosh TK, Noble LJ. Experimental fluid percussion brain injury: vascular disruption and neuronal and glial alterations. Brain Res. 482(2), 271-282 (1989).

54 Soares HD, Thomas M, Cloherty K, McIntosh TK. Development of prolonged focal cerebral edema and regional cation changes following experimental brain injury in the rat. J. Neurochem. 58(5), 1845-1852 (1992).

55 Morales DM, Marklund N, Lebold D et al. Experimental models of traumatic brain injury: do we really need to build a better mousetrap? Neuroscience 136(4), 971-989 (2005).

56 Lighthall JW. Controlled cortical impact: a new experimental brain injury model. J. Neurotrauma 5(1), 1-15 (1988).

57 Dixon CE, Clifton GL, Lighthall JW, Yaghmai AA, Hayes RL. A controlled cortical impact model of traumatic brain injury in the rat. J. Neurosci. Methods 39(3), 253-262 (1991).

58 Smith DH, Soares HD, Pierce JS et al. A model of parasagittal controlled cortical impact in the mouse: cognitive and histopathologic effects. J. Neurotrauma 12(2), 169-178 (1995).

59 Hannay HJ, Feldman Z, Phan P et al. Validation of a controlled cortical impact model of head injury in mice. J. Neurotrauma 16(11), 1103-1114 (1999).

60 Kochanek PM, Marion DW, Zhang W et al. Severe controlled cortical impact in rats: assessment of cerebral edema, blood flow, and contusion volume. J. Neurotrauma 12(6), 1015-1025 (1995).

61 Hall ED, Sullivan PG, Gibson TR, Pavel KM, Thompson BM, Scheff SW. Spatial and temporal characteristics of neurodegeneration after controlled cortical impact in mice: more than a focal brain injury. J. Neurotrauma 22(2), 252-265 (2005).

62 Marmarou A, Foda MA, van den Brink W, Campbell J, Kita H, Demetriadou K. A new model of diffuse brain injury in rats. Part I: pathophysiology and biomechanics. J. Neurosurg. 80(2), 291-300 (1994).

63 Foda MA, Marmarou A. A new model of diffuse brain injury in rats. Part II: morphological characterization. J. Neurosurg. 80(2), 301-313 (1994).

64 Barzo P, Marmarou A, Fatouros P, Corwin F, Dunbar J. Magnetic resonance imagingmonitored acute blood-brain barrier changes in experimental traumatic brain injury. J. Neurosurg. 85(6), 1113-1121 (1996).

65 Hoge CW, McGurk D, Thomas JL, Cox AL, Engel CC, Castro CA. Mild traumatic brain injury in U.S. Soldiers returning from Iraq. N. Engl. J. Med. 358(5), 453-463 (2008).

66 Cernak I, Wang Z, Jiang J, Bian X, Savic J. Ultrastructural and functional characteristics of blast injury-induced neurotrauma. J. Trauma 50(4), 695-706 (2001).

67 Saljo A, Bao F, Haglid KG, Hansson HA. Blast exposure causes redistribution of phosphorylated neurofilament subunits in neurons of the adult rat brain. J. Neurotrauma 17(8), 719-726 (2000).

68 Williams AJ, Hartings JA, Lu XC, Rolli ML, Tortella FC. Penetrating ballistic-like brain injury in the rat: differential time courses of hemorrhage, cell death, inflammation, and remote degeneration. J. Neurotrauma 23(12), 1828-1846 (2006).

69 Williams AJ, Ling GS, Tortella FC. Severity level and injury track determine outcome following a penetrating ballistic-like brain injury in the rat. Neurosci. Lett. 408(3), 183-188 (2006).

70 Williams AJ, Hartings JA, Lu XC, Rolli ML, Dave JR, Tortella FC. Characterization of a new rat model of penetrating ballistic brain injury. J. Neurotrauma 22(2), 313-331 (2005).

71 Allen IV, Scott R, Tanner JA. Experimental high-velocity missile head injury. Injury 14(2), 183-193 (1982).

72 Carey ME, Sarna GS, Farrell JB, Happel LT. Experimental missile wound to the brain J. Neurosurg. 71(5 Pt 1), 754-764 (1989).

73 Shear DA, Lu XC, Pedersen R et al. Severity profile of penetrating ballistic-like brain injury on neurofunctional outcome, bloodbrain barrier permeability, and brain edema formation. J. Neurotrauma 28(10), 2185-2195 (2011).

74 Williams AJ, Wei HH, Dave JR, Tortella FC. Acute and delayed neuroinflammatory response following experimental penetrating ballistic brain injury in the rat. J. Neuroinflammation 4, 17 (2007).

75 Gennarelli TA, Thibault LE, Adams JH, Graham DI, Thompson CJ, Marcincin RP. Diffuse axonal injury and traumatic coma in the primate. Ann. Neurol. 12(6), 564-574 (1982).

76 Ross DT, Meaney DF, Sabol MK, Smith DH, Gennarelli TA. Distribution of forebrain 
diffuse axonal injury following inertial closed head injury in miniature swine. Exp. Neurol. 126(2), 291-299 (1994).

77 Shapira Y, Shohami E, Sidi A, Soffer D, Freeman S, Cotev S. Experimental closed head injury in rats: mechanical, pathophysiologic, and neurologic properties. Crit. Care Med. 16(3), 258-265 (1988).

78 Shohami E, Novikov M, Bass R. Long-term effect of HU-211, a novel non-competitive NMDA antagonist, on motor and memory functions after closed head injury in the rat. Brain Res. 674(1), 55-62 (1995).

79 Lu D, Mahmood A, Qu C, Hong X, Kaplan D, Chopp M. Collagen scaffolds populated with human marrow stromal cells reduce lesion volume and improve functional outcome after traumatic brain injury. Neurosurgery 61(3), 596-602; discussion 602-603 (2007).

80 Lu D, Mahmood A, Wang L, Li Y, Lu M, Chopp M. Adult bone marrow stromal cells administered intravenously to rats after traumatic brain injury migrate into brain and improve neurological outcome. Neuroreport 12(3), 559-563 (2001).

81 Chen J, Li Y, Wang L et al. Therapeutic benefit of intravenous administration of bone marrow stromal cells after cerebral ischemia in rats. Stroke 32(4), 1005-1011 (2001).

82 Longa EZ, Weinstein PR, Carlson S, Cummins R. Reversible middle cerebral artery occlusion without craniectomy in rats. Stroke 20(1), 84-91 (1989).

83 Borlongan CV, Randall TS, Cahill DW, Sanberg PR. Asymmetrical motor behavior in rats with unilateral striatal excitotoxic lesions as revealed by the elevated body swing test. Brain Res. 676(1), 231-234 (1995).

84 Schallert T, Kozlowski DA, Humm JL, Cocke RR. Use-dependent structural events in recovery of function. Adv. Neurol. 73, 229-238 (1997).

85 Hillary FG, Medaglia JD, Gates K et al. Examining working memory task acquisition in a disrupted neural network. Brain 134(Pt 5), 1555-1570 (2011).

86 Germano AF, Dixon CE, d'Avella D, Hayes RL, Tomasello F. Behavioral deficits following experimental subarachnoid hemorrhage in the rat. J. Neurotrauma 11(3), 345-353 (1994).

87 Chen Y, Lomnitski L, Michaelson DM, Shohami E. Motor and cognitive deficits in apolipoprotein E-deficient mice after closed head injury. Neuroscience 80(4), 1255-1262 (1997).

88 Li Y, Chopp M, Chen J et al. Intrastriatal transplantation of bone marrow nonhematopoietic cells improves functional recovery after stroke in adult mice. J. Cereb. Blood Flow Metab. 20(9), 1311-1319 (2000).
89 Xiong Y, Mahmood A, Meng Y et al. Delayed administration of erythropoietin reducing hippocampal cell loss, enhancing angiogenesis and neurogenesis, and improving functional outcome following traumatic brain injury in rats: comparison of treatment with single and triple dose. J. Neurosurg. 113(3), 598-608 (2010).

90 Xiong Y, Mahmood A, Zhang Y et al. Effects of posttraumatic carbamylated erythropoietin therapy on reducing lesion volume and hippocampal cell loss, enhancing angiogenesis and neurogenesis, and improving functional outcome in rats following traumatic brain injury. J. Neurosurg. 114(2), 549-559 (2011).

91 Xiong Y, Zhang Y, Mahmood A et al. Neuroprotective and neurorestorative effects of thymosin $\beta 4$ treatment initiated 6 hours after traumatic brain injury in rats. J. Neurosurg. 116(5), 1081-1092 (2012).

92 Ning R, Xiong Y, Mahmood A et al. Erythropoietin promotes neurovascular remodeling and long-term functional recovery in rats following traumatic brain injury. Brain Res. 1384, 140-150 (2011).

93 Meng Y, Xiong Y, Mahmood A, Zhang Y, Qu C, Chopp M. Dose-dependent neurorestorative effects of delayed treatment of traumatic brain injury with recombinant human erythropoietin in rats. J. Neurosurg. 115(3), 550-560 (2011).

94 Zhang Y, Xiong Y, Mahmood A et al. Therapeutic effects of erythropoietin on histological and functional outcomes following traumatic brain injury in rats are independent of hematocrit. Brain Res. 1294, 153-164 (2009).

95 Chen J, Sanberg PR, Li Y et al. Intravenous administration of human umbilical cord blood reduces behavioral deficits after stroke in rats. Stroke 32(11), 2682-2688 (2001).

96 Chen J, Li Y, Wang L, Lu M, Zhang X, Chopp M. Therapeutic benefit of intracerebral transplantation of bone marrow stromal cells after cerebral ischemia in rats. J. Neurol. Sci. 189(1-2), 49-57 (2001).

97 Tupper DE, Wallace RB. Utility of the neurological examination in rats. Acta Neurobiol. Exp. (Wars.) 40(6), 999-1003 (1980).

98 McIntosh TK, Noble L, Andrews B, Faden AI. Traumatic brain injury in the rat: characterization of a midline fluid-percussion model. Cent. Nerv. Syst. Trauma 4(2), 119-134 (1987).

99 Saatman KE, Contreras PC, Smith DH et al. Insulin-like growth factor-1 (IGF-1) improves both neurological motor and cognitive outcome following experimental brain injury. Exp. Neurol. 147(2), 418-427 (1997).
100 Hayward NM, Immonen R, Tuunanen PI, Ndode-Ekane XE, Grohn O, Pitkanen A. Association of chronic vascular changes with functional outcome after traumatic brain injury in rats. J. Neurotrauma 27(12), 2203-2219 (2010).

101 Lenzlinger PM, Shimizu S, Marklund N et al. Delayed inhibition of Nogo-A does not alter injury-induced axonal sprouting but enhances recovery of cognitive function following experimental traumatic brain injury in rats. Neuroscience 134(3), 1047-1056 (2005).

102 Hoover RC, Motta M, Davis J et al. Differential effects of the anticonvulsant topiramate on neurobehavioral and histological outcomes following traumatic brain injury in rats. J. Neurotrauma 21(5), 501-512 (2004).

103 Okiyama K, Smith DH, Thomas MJ, McIntosh TK. Evaluation of a novel calcium channel blocker, (S)-emopamil, on regional cerebral edema and neurobehavioral function after experimental brain injury. J. Neurosurg. 77(4), 607-615 (1992).

104 Smith DH, Okiyama K, Thomas MJ, McIntosh TK. Effects of the excitatory amino acid receptor antagonists kynurenate and indole-2-carboxylic acid on behavioral and neurochemical outcome following experimental brain injury. J. Neurosci. 13(12), 5383-5392 (1993).

105 Sinson G, Voddi M, McIntosh TK. Nerve growth factor administration attenuates cognitive but not neurobehavioral motor dysfunction or hippocampal cell loss following fluid-percussion brain injury in rats. J. Neurochem. 65(5), 2209-2216 (1995).

106 Mattiasson GJ, Philips MF, Tomasevic G, Johansson BB, Wieloch T, McIntosh TK. The rotating pole test: evaluation of its effectiveness in assessing functional motor deficits following experimental head injury in the rat. J. Neurosci. Methods 95(1), 75-82 (2000).

107 Pierce JE, Smith DH, Trojanowski JQ, McIntosh TK. Enduring cognitive, neurobehavioral and histopathological changes persist for up to one year following severe experimental brain injury in rats. Neuroscience 87(2), 359-369 (1998).

- First paper using lateral fluid percussion injury demonstrating long-term spatial memory deficits using the Morris water maze.

108 Wahl F, Grosjean-Piot O, Bareyre F, Uzan A, Stutzmann JM. Enoxaparin reduces brain edema, cerebral lesions, and improves motor and cognitive impairments induced by a traumatic brain injury in rats. J. Neurotrauma 17(11), 1055-1065 (2000). 
109 Marklund N, Bareyre FM, Royo NC et al. Cognitive outcome following brain injury and treatment with an inhibitor of Nogo-A in association with an attenuated downregulation of hippocampal growthassociated protein-43 expression. J. Neurosurg. 107(4), 844-853 (2007).

110 Rau TF, Kothiwal AS, Rova AR, Brooks DM, Poulsen DJ. Treatment with low-dose methamphetamine improves behavioral and cognitive function after severe traumatic brain injury. J. Trauma Acute Care Surg. 73(2 Suppl. 1), S165-S172 (2012).

111 Riess P, Bareyre FM, Saatman KE et al. Effects of chronic, post-injury cyclosporin A administration on motor and sensorimotor function following severe, experimental traumatic brain injury. Restor. Neurol. Neurosci. 18(1), 1-8 (2001).

112 Schütz C, Stover JF, Thompson HJ et al. Acute, transient hemorrhagic hypotension does not aggravate structural damage or neurologic motor deficits but delays the longterm cognitive recovery following mild to moderate traumatic brain injury. Crit. Care Med. 34(2), 492-501 (2006).

113 Keck CA, Thompson HJ, Pitkanen A et al. The novel antiepileptic agent RWJ-333369-A, but not its analog RWJ-333369, reduces regional cerebral edema without affecting neurobehavioral outcome or cell death following experimental traumatic brain injury. Restor. Neurol. Neurosci. 25(2), 77-90 (2007).

114 Longhi L, Watson DJ, Saatman KE et al. Ex vivo gene therapy using targeted engraftment of NGF-expressing human NT2N neurons attenuates cognitive deficits following traumatic brain injury in mice. J. Neurotrauma 21(12), 1723-1736 (2004).

115 Shelton SB, Pettigrew DB, Hermann AD et al. A simple, efficient tool for assessment of mice after unilateral cortex injury. J. Neurosci. Methods 168(2), 431-442 (2008).

116 Longhi L, Gesuete R, Perego C et al. Longlasting protection in brain trauma by endotoxin preconditioning. J. Cereb. Blood Flow Metab. 31(9), 1919-1929 (2011).

117 Bradwell DJ, Kim H, Sirk AH, Sadoway DR. Magnesium-antimony liquid metal battery for stationary energy storage. J. Am. Chem. Soc. 134(4), 1895-1897 (2012).

118 Singleton RH, Yan HQ, Fellows-Mayle W, Dixon CE. Resveratrol attenuates behavioral impairments and reduces cortical and hippocampal loss in a rat controlled cortical impact model of traumatic brain injury. J. Neurotrauma 27(6), 1091-1099 (2010).

119 Colombel C, Lalonde R, Caston J. The effects of unilateral removal of the cerebellar hemispheres on motor functions and weight gain in rats. Brain Res. 950(1-2), 231-238 (2002).

120 Lekic T, Rolland W, Hartman R et al. Characterization of the brain injury, neurobehavioral profiles, and histopathology in a rat model of cerebellar hemorrhage. Exp. Neurol. 227(1), 96-103 (2011).

121 Cheng JP, Shaw KE, Monaco CM et al. A relatively brief exposure to environmental enrichment after experimental traumatic brain injury confers long-term cognitive benefits. J. Neurotrauma 29(17), 2684-2688 (2012).

122 Hallam TM, Floyd CL, Folkerts MM et al. Comparison of behavioral deficits and acute neuronal degeneration in rat lateral fluid percussion and weight-drop brain injury models. J. Neurotrauma 21(5), 521-539 (2004).

123 Lee LL, Galo E, Lyeth BG, Muizelaar JP, Berman RF. Neuroprotection in the rat lateral fluid percussion model of traumatic brain injury by SNX-185, an N-type voltage-gated calcium channel blocker. Exp. Neurol. 190(1), 70-78 (2004).

124 Fox GB, Fan L, Levasseur RA, Faden AI. Sustained sensory/motor and cognitive deficits with neuronal apoptosis following controlled cortical impact brain injury in the mouse. J. Neurotrauma 15(8), 599-614 (1998).

125 Fox GB, Faden AI. Traumatic brain injury causes delayed motor and cognitive impairment in a mutant mouse strain known to exhibit delayed Wallerian degeneration. J. Neurosci. Res. 53(6), 718-727 (1998).

126 Fox GB, Fan L, Levasseur RA, Faden AI. Effect of traumatic brain injury on mouse spatial and nonspatial learning in the Barnes circular maze. J. Neurotrauma 15(12), 1037-1046 (1998).

127 Fox GB, Levasseur RA, Faden AI. Behavioral responses of C57BL/6, FVB/N, and $129 /$ SvEMS mouse strains to traumatic brain injury: implications for gene targeting approaches to neurotrauma. J. Neurotrauma 16(5), 377-389 (1999).

128 Zhao Z, Loane DJ, Murray MG 2nd, Stoica BA, Faden AI. Comparing the predictive value of multiple cognitive, affective, and motor tasks after rodent traumatic brain injury. J. Neurotrauma 29(15), 2475-2489 (2012).

129 Bao F, Shultz SR, Hepburn JD et al. A CD11d monoclonal antibody treatment reduces tissue injury and improves neurological outcome after fluid percussion brain injury in rats. J. Neurotrauma 29(14), 2375-2392 (2012).
130 Lyeth BG, Gong QZ, Shields S, Muizelaar JP, Berman RF. Group I metabotropic glutamate antagonist reduces acute neuronal degeneration and behavioral deficits after traumatic brain injury in rats. Exp. Neurol. 169(1), 191-199 (2001).

131 Shultz SR, Bao F, Weaver LC, Cain DP, Brown A. Treatment with an anti-CD11d integrin antibody reduces neuroinflammation and improves outcome in a rat model of repeated concussion. J. Neuroinflammation 10, 26 (2013).

132 Barth TM, Jones TA, Schallert T. Functional subdivisions of the rat somatic sensorimotor cortex. Behav. Brain Res. 39(1), 73-95 (1990).

133 Hoane MR, Becerra GD, Shank JE et al. Transplantation of neuronal and glial precursors dramatically improves sensorimotor function but not cognitive function in the traumatically injured brain. J. Neurotrauma 21(2), 163-174 (2004).

134 Hanell A, Clausen F, Bjork M et al. Genetic deletion and pharmacological inhibition of Nogo-66 receptor impairs cognitive outcome after traumatic brain injury in mice. J. Neurotrauma 27(7), 1297-1309 (2010).

135 Woodlee MT, Asseo-Garcia AM, Zhao X, Liu SJ, Jones TA, Schallert T. Testing forelimb placing 'across the midline' reveals distinct, lesion-dependent patterns of recovery in rats. Exp. Neurol. 191(2), 310-317 (2005).

136 Carballosa Gonzalez MM, Blaya MO, Alonso OF, Bramlett HM, Hentall ID. Midbrain raphe stimulation improves behavioral and anatomical recovery from fluid-percussion brain injury. J. Neurotrauma 30(2), 119-130 (2013).

137 Xiong Y, Lu D, Qu C et al. Effects of erythropoietin on reducing brain damage and improving functional outcome after traumatic brain injury in mice. J. Neurosurg. 109(3), 510-521 (2008).

138 Xiong Y, Mahmood A, Lu D et al. Histological and functional outcomes after traumatic brain injury in mice null for the erythropoietin receptor in the central nervous system. Brain Res. 1230, 247-257 (2008).

139 Xiong Y, Mahmood A, Meng Y et al. Treatment of traumatic brain injury with thymosin $\beta(4)$ in rats. J. Neurosurg. 114(1), 102-115 (2011).

140 De Ryck M, Van Reempts J, Duytschaever H, Van Deuren B, Clincke G. Neocortical localization of tactile/proprioceptive limb placing reactions in the rat. Brain Res. 573(1), 44-60 (1992).

141 Hoffman SW, Fulop Z, Stein DG. Bilateral frontal cortical contusion in rats: behavioral and anatomic consequences. J. Neurotrauma 11(4), 417-431 (1994). 
142 Washington PM, Forcelli PA, Wilkins T, Zapple D, Parsadanian M, Burns MP. The effect of injury severity on behavior: a phenotypic study of cognitive and emotional deficits after mild, moderate and severe controlled cortical impact injury in mice. J. Neurotrauma (2012).

143 Vink R, O'Connor CA, Nimmo AJ, Heath DL. Magnesium attenuates persistent functional deficits following diffuse traumatic brain injury in rats. Neurosci. Lett. 336(1), 41-44 (2003).

144 O'Connor C, Heath DL, Cernak I, Nimmo AJ, Vink R. Effects of daily versus weekly testing and pre-training on the assessment of neurologic impairment following diffuse traumatic brain injury in rats. J. Neurotrauma 20(10), 985-993 (2003).

145 Hamm RJ, Pike BR, O’Dell DM, Lyeth BG, Jenkins LW. The rotarod test: an evaluation of its effectiveness in assessing motor deficits following traumatic brain injury. J. Neurotrauma 11(2), 187-196 (1994).

146 Brody DL, MacDonald C, Kessens CC et al. Electromagnetic controlled cortical impact device for precise, graded experimental traumatic brain injury. J. Neurotrauma 24(4), 657-673 (2007).

147 Shear DA, Tate CC, Tate MC et al. Stem cell survival and functional outcome after traumatic brain injury is dependent on transplant timing and location. Restor. Neurol. Neurosci. 29(4), 215-225 (2011).

148 Laurer HL, Bareyre FM, Lee VM et al. Mild head injury increasing the brain's vulnerability to a second concussive impact. J. Neurosurg. 95(5), 859-870 (2001).

149 Philips MF, Mattiasson G, Wieloch T et al. Neuroprotective and behavioral efficacy of nerve growth factor-transfected hippocampal progenitor cell transplants after experimental traumatic brain injury. J. Neurosurg. 94(5), 765-774 (2001)

150 Mannix RC, Zhang J, Park J et al. Agedependent effect of apolipoprotein E4 on functional outcome after controlled cortical impact in mice. J. Cereb. Blood Flow Metab. 31(1), 351-361 (2011).

151 Jenkinson EW, Glickstein M. Whiskers, barrels, and cortical efferent pathways in gap crossing by rats. J. Neurophysiol. 84(4), 1781-1789 (2000).

152 Barnes CA. Memory deficits associated with senescence: a neurophysiological and behavioral study in the rat. J. Comp. Physiol. Psychol. 93(1), 74-104 (1979).

153 Cahill L. Neurobiological mechanisms of emotionally influenced, long-term memory. Prog. Brain Res. 126, 29-37 (2000).

154 Morris R. Developments of a water-maze procedure for studying spatial learning in the rat. J. Neurosci. Methods 11(1), 47-60 (1984).

155 Vorhees CV, Williams MT. Morris water maze: procedures for assessing spatial and related forms of learning and memory. Nat. Protoc. 1(2), 848-858 (2006).

156 Nadel L, Hardt O. Update on memory systems and processes

Neuropsychopharmacology 36(1), 251-273 (2011).

157 D'Hooge R, De Deyn PP. Applications of the Morris water maze in the study of learning and memory. Brain Res. Brain Res. Rev. 36(1), 60-90 (2001).

158 Sinson G, Perri BR, Trojanowski JQ, Flamm ES, McIntosh TK. Improvement of cognitive deficits and decreased cholinergic neuronal cell loss and apoptotic cell death following neurotrophin infusion after experimental traumatic brain injury. J. Neurosurg. 86(3), 511-518 (1997).

159 Phillips LL, Lyeth BG, Hamm RJ, Jiang JY, Povlishock JT, Reeves TM. Effect of prior receptor antagonism on behavioral morbidity produced by combined fluid percussion injury and entorhinal cortical lesion. J. Neurosci. Res. 49(2), 197-206 (1997).

160 Sanders MJ, Dietrich WD, Green EJ. Cognitive function following traumatic brain injury: effects of injury severity and recovery period in a parasagittal fluid-percussive injury model. J. Neurotrauma 16(10), 915-925 (1999).

161 Schmidt RH, Scholten KJ, Maughan PH. Time course for recovery of water maze performance and central cholinergic innervation after fluid percussion injury. J. Neurotrauma 16(12), 1139-1147 (1999).

162 Browne KD, Leoni MJ, Iwata A, Chen XH, Smith DH. Acute treatment with $\mathrm{MgSO}_{4}$ attenuates long-term hippocampal tissue loss after brain trauma in the rat. J. Neurosci. Res. 77(6), 878-883 (2004).

163 Giza CC, Griesbach GS, Hovda DA. Experience-dependent behavioral plasticity is disturbed following traumatic injury to the immature brain. Behav. Brain Res. 157(1), 11-22 (2005).

164 Thompson HJ, LeBold DG, Marklund N, Morales DM, Hagner AP, McIntosh TK. Cognitive evaluation of traumatically braininjured rats using serial testing in the Morris water maze. Restor. Neurol. Neurosci. 24(2), 109-114 (2006).

165 Browne KD, Iwata A, Putt ME, Smith DH. Chronic ibuprofen administration worsens cognitive outcome following traumatic brain injury in rats. Exp. Neurol. 201(2), 301-307 (2006).

166 Baranova AI, Whiting MD, Hamm RJ. Delayed, post-injury treatment with aniracetam improves cognitive performance after traumatic brain injury in rats. J. Neurotrauma 23(8), 1233-1240 (2006).

167 Sun D, McGinn MJ, Zhou Z, Harvey HB, Bullock MR, Colello RJ. Anatomical integration of newly generated dentate granule neurons following traumatic brain injury in adult rats and its association to cognitive recovery. Exp. Neurol. 204(1), 264-272 (2007).

168 Reid WM, Hamm RJ. Post-injury atomoxetine treatment improves cognition following experimental traumatic brain injury. J. Neurotrauma 25(3), 248-256 (2008).

169 Hamm RJ, Dixon CE, Gbadebo DM et al. Cognitive deficits following traumatic brain injury produced by controlled cortical impact. J. Neurotrauma 9(1), 11-20 (1992).

170 Dixon CE, Hamm RJ, Taft WC, Hayes RL. Increased anticholinergic sensitivity following closed skull impact and controlled cortical impact traumatic brain injury in the rat. J. Neurotrauma 11(3), 275-287 (1994).

171 Dixon CE, Kochanek PM, Yan HQ et al. One-year study of spatial memory performance, brain morphology, and cholinergic markers after moderate controlled cortical impact in rats. J. Neurotrauma 16(2), 109-122 (1999).

- First paper using controlled cortical impact demonstrating long-term deficits in spatial memory using the Morris water maze.

172 Longhi L, Perego C, Zanier ER et al. Neuroprotective effect of C1-inhibitor following traumatic brain injury in mice. Acta Neurochir. Suppl. 102, 381-384 (2008).

173 Longhi L, Ortolano F, Zanier ER, Perego C, Stocchetti N, De Simoni MG. Effect of traumatic brain injury on cognitive function in mice lacking p 55 and p75 tumor necrosis factor receptors. Acta Neurochir. Suppl. 102, 409-413 (2008).

174 Marklund N, Morales D, Clausen F et al. Functional outcome is impaired following traumatic brain injury in aging Nogo-A/B-deficient mice. Neuroscience 163(2), 540-551 (2009).

175 Chauhan NB, Gatto R. Synergistic benefits of erythropoietin and simvastatin after traumatic brain injury. Brain Res. 1360, 177-192 (2010).

176 Chauhan NB, Gatto R. Restoration of cognitive deficits after statin feeding in TBI. Restor. Neurol. Neurosci. 29(1), 23-34 (2011).

177 Byrnes KR, Loane DJ, Stoica BA, Zhang J, Faden AI. Delayed mGluR5 activation limits neuroinflammation and neurodegeneration after traumatic brain injury. J. Neuroinflammation 9, 43 (2012). 
178 Zhang Y, Chopp M, Mahmood A, Meng Y, $\mathrm{Qu}$ C, Xiong Y. Impact of inhibition of erythropoietin treatment-mediated neurogenesis in the dentate gyrus of the hippocampus on restoration of spatial learning after traumatic brain injury. Exp. Neurol. 235(1), 336-344 (2012).

179 Tomasevic G, Laurer HL, Mattiasson G, Steeg H, Wieloch T, McIntosh TK. Delayed neuromotor recovery and increased memory acquisition dysfunction following experimental brain trauma in mice lacking the DNA repair gene XPA. J. Neurosurg. 116(6), 1368-1378 (2012).

180 Xiong Y, Zhang Y, Mahmood A, Meng Y, Qu C, Chopp M. Erythropoietin mediates neurobehavioral recovery and neurovascular remodeling following traumatic brain injury in rats by increasing expression of vascular endothelial growth factor. Transl. Stroke Res. 2(4), 619-632 (2011).

181 Han RZ, Hu JJ, Weng YC, Li DF, Huang Y. NMDA receptor antagonist MK-801 reduces neuronal damage and preserves learning and memory in a rat model of traumatic brain injury. Neurosci. Bull. 25(6), 367-375 (2009).

182 Adelson PD, Dixon CE, Kochanek PM. Long-term dysfunction following diffuse traumatic brain injury in the immature rat. J. Neurotrauma 17(4), 273-282 (2000).

183 Maughan PH, Scholten KJ, Schmidt RH. Recovery of water maze performance in aged versus young rats after brain injury with the impact acceleration model. J. Neurotrauma 17(12), 1141-1153 (2000).

184 Zohar O, Schreiber S, Getslev V, Schwartz JP, Mullins PG, Pick CG. Closed-head minimal traumatic brain injury produces long-term cognitive deficits in mice. Neuroscience 118(4), 949-955 (2003).

185 Zohar O, Getslev V, Miller AL, Schreiber S, Pick CG. Morphine protects for head trauma induced cognitive deficits in mice. Neurosci. Lett. 394(3), 239-242 (2006).

186 Huh JW, Raghupathi R. Chronic cognitive deficits and long-term histopathological alterations following contusive brain injury in the immature rat. J. Neurotrauma 24(9), 1460-1474 (2007).

187 Raghupathi R, Huh JW. Diffuse brain injury in the immature rat: evidence for an age-atinjury effect on cognitive function and histopathologic damage. J. Neurotrauma 24(10), 1596-1608 (2007).

188 Maruichi K, Kuroda S, Chiba Y et al. Transplanted bone marrow stromal cells improves cognitive dysfunction due to diffuse axonal injury in rats. Neuropathology 29(4), 422-432 (2009).

189 Shultz SR, Bao F, Omana V, Chiu C, Brown A, Cain DP. Repeated mild lateral fluid percussion brain injury in the rat causes cumulative long-term behavioral impairments, neuroinflammation, and cortical loss in an animal model of repeated concussion. J. Neurotrauma 29(2), 281-294 (2012).

190 Hamm RJ, Pike BR, Temple MD, O’Dell DM, Lyeth BG. The effect of post-injury kindled seizures on cognitive performance of traumatically brain-injured rats. Exp. Neurol. 136(2), 143-148 (1995).

191 Meehan WP 3rd, Zhang J, Mannix R, Whalen MJ. Increasing recovery time between injuries improves cognitive outcome after repetitive mild concussive brain injuries in mice. Neurosurgery $71(4), 885-891$ (2012).

192 Uryu K, Laurer H, McIntosh T et al. Repetitive mild brain trauma accelerates $\mathrm{A} \beta$ deposition, lipid peroxidation, and cognitive impairment in a transgenic mouse model of Alzheimer amyloidosis. J. Neurosci. 22(2), 446-454 (2002).

193 Griesbach GS, Hovda DA, Molteni R, Wu A, Gomez-Pinilla F. Voluntary exercise following traumatic brain injury: brainderived neurotrophic factor upregulation and recovery of function. Neuroscience 125(1), 129-139 (2004).

194 Immonen RJ, Kharatishvili I, Grohn H, Pitkanen A, Grohn OH. Quantitative MRI predicts long-term structural and functional outcome after experimental traumatic brain injury. Neuroimage 45(1), 1-9 (2009).

195 Yamaki T, Murakami N, Iwamoto Y et al. Evaluation of learning and memory dysfunction and histological findings in rats with chronic stage contusion and diffuse axonal injury. Brain Res. 752(1-2), 151-160 (1997).

196 Yamaki T, Murakami N, Iwamoto Y et al. Cognitive dysfunction and histological findings in rats with chronic-stage contusion and diffuse axonal injury. Brain Res. Brain Res. Protoc. 3(1), 100-106 (1998).

197 Ennaceur A, Neave N, Aggleton JP. Neurotoxic lesions of the perirhinal cortex do not mimic the behavioural effects of fornix transection in the rat. Behav. Brain Res. 80(1-2), 9-25 (1996).

198 Edut S, Rubovitch V, Schreiber S, Pick CG. The intriguing effects of ecstasy (MDMA) on cognitive function in mice subjected to a minimal traumatic brain injury (mTBI). Psychopharmacology (Berl.) 214(4), 877-889 (2011).

199 Hamm RJ, Lyeth BG, Jenkins LW, O’Dell DM, Pike BR. Selective cognitive impairment following traumatic brain injury in rats. Behav. Brain Res. 59(1-2), 169-173 (1993).
200 Milman A, Rosenberg A, Weizman R, Pick CG. Mild traumatic brain injury induces persistent cognitive deficits and behavioral disturbances in mice. J. Neurotrauma 22(9), 1003-1010 (2005).

201 Milman A, Zohar O, Maayan R, Weizman R, Pick CG. DHEAS repeated treatment improves cognitive and behavioral deficits after mild traumatic brain injury. Eur. Neuropsychopharmacol. 18(3), 181-187 (2008).

202 Baratz R, Rubovitch V, Frenk H, Pick CG. The influence of alcohol on behavioral recovery after $\mathrm{mTBI}$ in mice. J. Neurotrauma 27(3), 555-563 (2010).

203 Floresco SB, Seamans JK, Phillips AG. Selective roles for hippocampal, prefrontal cortical, and ventral striatal circuits in radialarm maze tasks with or without a delay. J. Neurosci. 17(5), 1880-1890 (1997).

204 Malleret G, Hen R, Guillou JL, Segu L, Buhot MC. 5-HT1B receptor knock-out mice exhibit increased exploratory activity and enhanced spatial memory performance in the Morris water maze. J. Neurosci. 19(14), 6157-6168 (1999).

205 Tanaka K, Yagi T, Shimakoshi R et al. Effects of galantamine on L-NAME-induced behavioral impairment in Y-maze task in mice. Neurosci. Lett. 462(3), 235-238 (2009).

206 Lloyd E, Somera-Molina K, Van Eldik LJ, Watterson DM, Wainwright MS. Suppression of acute proinflammatory cytokine and chemokine upregulation by post-injury administration of a novel small molecule improves long-term neurologic outcome in a mouse model of traumatic brain injury. J. Neuroinflammation 5, 28 (2008).

207 Moscarello JM, Ledoux JE. Active avoidance learning requires prefrontal suppression of amygdala-mediated defensive reactions. J. Neurosci. 33(9), 3815-3823 (2013).

208 Steru L, Chermat R, Thierry B, Simon P. The tail suspension test: a new method for screening antidepressants in mice. Psychopharmacology (Berl.) 85(3), 367-370 (1985).

209 Nichols JE, Niles JA, Dewitt D et al. Neurogenic and neuro-protective potential of a novel subpopulation of peripheral bloodderived CD133 ${ }^{+} \mathrm{ABCG} 2^{+} \mathrm{CXCR} 4^{+}$ mesenchymal stem cells: development of autologous cell-based therapeutics for traumatic brain injury. Stem Cell Res. Ther. 4(1), 3 (2013).

210 Sontag C, Nguyen HX, Kamei N, Uchida N, Anderson AJ, Cummings BJ. Immunosuppressants affect human neural stem cells in vitro, but not in an in vivo model of spinal cord injury. Stem Cells Transl. Med. (2013) (In press). 
211 Weick JP, Liu Y, Zhang SC. Human embryonic stem cell-derived neurons adopt and regulate the activity of an established neural network. Proc. Natl Acad. Sci. USA 108(50), 20189-20194 (2011).

212 Wang S, Bates J, Li X et al. Human iPSCderived oligodendrocyte progenitor cells can myelinate and rescue a mouse model of congenital hypomyelination. Cell Stem Cell 12(2), 252-264 (2013).

213 Yasuhara T, Matsukawa N, Hara K et al. Transplantation of human neural stem cells exerts neuroprotection in a rat model of Parkinson's disease. J. Neurosci. 26(48), 12497-12511 (2006).

214 Horie N, Pereira MP, Niizuma K et al. Transplanted stem cell-secreted vascular endothelial growth factor effects poststroke recovery, inflammation, and vascular repair. Stem Cells 29(2), 274-285 (2011).

215 Andres RH, Horie N, Slikker W et al. Human neural stem cells enhance structural plasticity and axonal transport in the ischaemic brain. Brain 134(Pt 6), 1777-1789 (2011).

216 Nasonkin I, Mahairaki V, Xu L et al. Longterm, stable differentiation of human embryonic stem cell-derived neural precursors grafted into the adult mammalian neostriatum. Stem Cells 27(10), 2414-2426 (2009).

217 Mahmood A, Lu D, Lu M, Chopp M. Treatment of traumatic brain injury in adult rats with intravenous administration of human bone marrow stromal cells. Neurosurgery 53(3), 697-702; discussion 702-703 (2003).

218 Hong SQ, Zhang HT, You J et al. Comparison of transdifferentiated and untransdifferentiated human umbilical mesenchymal stem cells in rats after traumatic brain injury. Neurochem. Res. 36(12), 2391-2400 (2011).

219 Wennersten A, Holmin S, Al Nimer F, Meijer X, Wahlberg LU, Mathiesen T. Sustained survival of xenografted human neural stem/progenitor cells in experimental brain trauma despite discontinuation of immunosuppression. Exp. Neurol. 199(2), 339-347 (2006).

220 Zhang C, Saatman KE, Royo NC et al. Delayed transplantation of human neurons following brain injury in rats: a long-term graft survival and behavior study. J. Neurotrauma 22(12), 1456-1474 (2005).

221 Skardelly M, Gaber K, Burdack S et al. Longterm benefit of human fetal neuronal progenitor cell transplantation in a clinically adapted model after traumatic brain injury. J. Neurotrauma 28(3), 401-414 (2011).

- Report of transplanted human fetal-derived neural progenitor cells in rats following controlled cortical impact demonstrating functional improvement on rotarod and modified neurological severity scores at 12 weeks postinjury.

222 Mahmood A, Lu D, Qu C, Goussev A, Chopp M. Human marrow stromal cell treatment provides long-lasting benefit after traumatic brain injury in rats. Neurosurgery 57(5), 1026-1031; discussion 1026-1031 (2005).

- Report of transplanted human marrow stromal cells in rats following controlled cortical impact demonstrating functional improvement of modified neurological severity scores at 12 weeks postinjury.

223 Sharp J, Frame J, Siegenthaler M, Nistor G, Keirstead HS. Human embryonic stem cellderived oligodendrocyte progenitor cell transplants improve recovery after cervical spinal cord injury. Stem Cells 28(1), 152-163 (2010).

224 Sullivan PG, Rabchevsky AG, Hicks RR, Gibson TR, Fletcher-Turner A, Scheff SW. Dose-response curve and optimal dosing regimen of cyclosporin A after traumatic brain injury in rats. Neuroscience 101(2), 289-295 (2000).

225 Albensi BC, Sullivan PG, Thompson MB, Scheff SW, Mattson MP. Cyclosporin ameliorates traumatic brain-injury-induced alterations of hippocampal synaptic plasticity. Exp. Neurol. 162(2), 385-389 (2000).

226 Zhao H, Yao R, Cao X, Wu G. Neuroimmune modulation following traumatic stress in rats: evidence for an immunoregulatory cascade mediated by c-Src, miRNA222 and PAK1. J. Neuroinflammation 8, 159 (2011).

227 Lu J, Goh SJ, Tng PY, Deng YY, Ling EA, Moochhala S. Systemic inflammatory response following acute traumatic brain injury. Front. Biosci. 14, 3795-3813 (2009).

228 Esmaeili A, Dadkhahfar S, Fadakar K, Rezaei N. Post-stroke immunodeficiency: effects of sensitization and tolerization to brain antigens. Int. Rev. Immunol. 31(5), 396-409 (2012).

229 Morganti-Kossmann MC, Rancan M, Stahel $\mathrm{PF}$, Kossmann T. Inflammatory response in acute traumatic brain injury: a double-edged sword. Curr. Opin. Crit. Care 8(2), 101-105 (2002).

230 Hagan M, Wennersten A, Meijer X, Holmin S, Wahlberg L, Mathiesen T. Neuroprotection by human neural progenitor cells after experimental contusion in rats. Neurosci. Lett. 351(3), 149-152 (2003).

231 Lu D, Sanberg PR, Mahmood A et al. Intravenous administration of human umbilical cord blood reduces neurological deficit in the rat after traumatic brain injury. Cell Transplant. 11(3), 275-281 (2002).

232 Watson DJ, Longhi L, Lee EB et al. Genetically modified NT2N human neuronal cells mediate long-term gene expression as CNS grafts in vivo and improve functional cognitive outcome following experimental traumatic brain injury. J. Neuropathol. Exp. Neuro. 62(4), 368-380 (2003).

233 Qu C, Xiong Y, Mahmood A et al. Treatment of traumatic brain injury in mice with bone marrow stromal cell-impregnated collagen scaffolds. J. Neurosurg. 111(4), 658-665 (2009).

234 Kim HJ, Lee JH, Kim SH. Therapeutic effects of human mesenchymal stem cells on traumatic brain injury in rats: secretion of neurotrophic factors and inhibition of apoptosis. J. Neurotrauma 27(1), 131-138 (2010).

235 Heile AM, Wallrapp C, Klinge PM et al. Cerebral transplantation of encapsulated mesenchymal stem cells improves cellular pathology after experimental traumatic brain injury. Neurosci. Lett. 463(3), 176-181 (2009).

236 Walker PA, Shah SK, Jimenez F et al. Intravenous multipotent adult progenitor cell therapy for traumatic brain injury: preserving the blood brain barrier via an interaction with splenocytes. Exp. Neurol. 225(2), 341-352 (2010).

237 Qu C, Mahmood A, Liu XS et al. The treatment of TBI with human marrow stromal cells impregnated into collagen scaffold: functional outcome and gene expression profile. Brain Res. 1371, 129-139 (2011).

238 Li L, Jiang Q, Qu CS et al. Transplantation of marrow stromal cells restores cerebral blood flow and reduces cerebral atrophy in rats with traumatic brain injury: in vivo MRI study. J. Neurotrauma 28(4), 535-545 (2011).

239 Jiang Q, Qu C, Chopp M et al. MRI evaluation of axonal reorganization after bone marrow stromal cell treatment of traumatic brain injury. NMR Biomed. 24(9), 1119-1128 (2011).

240 Zanier ER, Montinaro M, Vigano M et al. Human umbilical cord blood mesenchymal stem cells protect mice brain after trauma. Crit. Care Med. 39(11), 2501-2510 (2011).

241 Poltavtseva RA, Silachev DN, Pavlovich SV et al. Neuroprotective effect of mesenchymal and neural stem and progenitor cells on sensorimotor recovery after brain injury. Bull. Exp. Biol. Med. 153(4), 586-590 (2012).

242 Hung CJ, Yao CL, Cheng FC, Wu ML, Wang TH, Hwang SM. Establishment of immortalized mesenchymal stromal cells with red fluorescence protein expression for in vivo transplantation and tracing in the rat model with traumatic brain injury. Cytotherapy 12(4), 455-465 (2010).

243 Muir JK, Raghupathi R, Saatman KE et al. Terminally differentiated human neurons survive and integrate following transplantation into the traumatically injured rat brain. J. Neurotrauma 16(5), 403-414 (1999). 
244 Gao J, Prough DS, McAdoo DJ et al. Transplantation of primed human fetal neural stem cells improves cognitive function in rats after traumatic brain injury. Exp. Neurol. 201(2), 281-292 (2006).

245 Wang E, Gao J, Yang Q et al. Molecular mechanisms underlying effects of neural stem cells against traumatic axonal injury. J. Neurotrauma 29(2), 295-312 (2012).

246 Chen Z, Tortella FC, Dave JR et al. Human amnion-derived multipotent progenitor cell treatment alleviates traumatic brain injury-induced axonal degeneration. J. Neurotrauma 26(11), 1987-1997 (2009).

247 Chen Z, Lu XC, Shear DA et al. Synergism of human amnion-derived multipotent progenitor (AMP) cells and a collagen scaffold in promoting brain wound recovery: pre-clinical studies in an experimental model of penetrating ballistic-like brain injury. Brain Res. 1368, 71-81 (2011).
248 Wennersten A, Meier X, Holmin S, Wahlberg L, Mathiesen T. Proliferation, migration, and differentiation of human neural stem/ progenitor cells after transplantation into a rat model of traumatic brain injury. J. Neurosurg. 100(1), 88-96 (2004).

249 Al Nimer F, Wennersten A, Holmin S, Meijer X, Wahlberg L, Mathiesen T. MHC expression after human neural stem cell transplantation to brain contused rats. Neuroreport 15(12), 1871-1875 (2004).

250 Lundberg J, Le Blanc K, Soderman M, Andersson T, Holmin S. Endovascular transplantation of stem cells to the injured rat CNS. Neuroradiology 51(10), 661-667 (2009).

251 Bramlett HM, Green EJ, Dietrich WD. Hippocampally dependent and independent chronic spatial navigational deficits following parasagittal fluid percussion brain injury in the rat. Brain Res. 762(1-2), 195-202 (1997).

\section{Websites}

301 CCCRP. Neuroprotection Research. https://ccc.amedd.army.mil/task-areas/ neuroprotection-research.jspx (Accessed 28 March 2013).

302 DVBIC. DoD Worldwide Numbers for TBI. www.dvbic.org/dod-worldwide-numbers-tbi (Accessed 28 March 2013).

303 ClinicalTrials.gov. www.clinicaltrials.gov

304 RIGOR. Improving the quality of NINDSsupported preclinical and clinical research through rigorous study design and transparent reporting. www.ninds.nih.gov/funding/transparency_ in_reporting_guidance.pdf (Accessed 28 March 2013) 